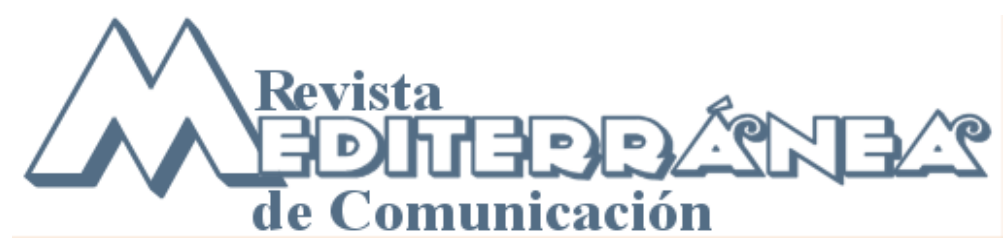

\title{
La representación televisiva de los inmigrantes africanos: invisibilidad, desconocimiento y precariedad
}

\section{The television representation of African immigrants: invisibility, ignorance and uncertainty}

\author{
Vanessa Rodríguez Breijo \\ Doctora en Ciencias de la Información \\ Miembro fundador de la Sociedad Latina de Comunicación Social \\ Universidad de La Laguna, ULL \\ vrbreijo@ull.es
}

\section{Resumen}

La imagen televisiva de los inmigrantes africanos se caracteriza por su aparición poco frecuente, la falta de información sobre ellos, la precariedad de sus condiciones de trabajo, su tendencia a desempeñar el rol de víctimas y una mayor incidencia de transgresiones a la ley respecto a otros grupos. Estos datos proceden del estudio de la representación de los inmigrantes en este medio. La técnica utilizada fue el análisis de contenido de una muestra de la programación con mayor audiencia, en la que se incluyeron todos los géneros televisivos. Los resultados correspondientes a los africanos los vincularon escasamente con el mundo laboral, lo que no contribuye a que los nativos los valoren como ciudadanos útiles y necesarios. No se promovió el interés por el conocimiento de este colectivo, ni la noción de que ya forman parte de la sociedad; debido a su poca visibilidad y a los exiguos datos ofrecidos sobre ellos. En lugar de resaltar sus aportes, se enfatizó su recurrencia a ayudas gubernamentales y su dependencia, transmitiendo una idea de competencia por los recursos y de normalidad de su situación de desigualdad. Finalmente, sus más frecuentes acciones ilegales podrían estar justificando esas peores condiciones de integración, liberando de responsabilidad a la sociedad receptora.

\section{Palabras clave}

Televisión; medio; imagen; población; ética; periodismo; España.

\section{Abstract}

The television image of African immigrants is characterized by its infrequent occurrence, the lack of information about them, poor working conditions, their tendency to play the role of victims and a higher incidence of violations of the law regarding other groups. This data comes from examining the representation of immigrants in this media. The technique used 
was content analysis of a sample of the most watched programs, which included all television genres. The results for the Africans pointed a weak link with the workplace, which doesn't contribute to their valuing as necessary and useful citizens. The interest in knowledge of this group wasn't promoted, nor the notion that now forms part of society, due to low visibility and the limited information provided on them. Instead of highlighting their contributions, be emphasized their use on government assistance and their dependence, conveying the idea of the competition for resources and normalcy of their situation of inequality. Finally, its illegal actions, more commons than in the other groups, could be justifying these worst conditions of integration, freeing of responsibility to the host society.

\section{Key Words}

Television; media; image; population; ethics; journalism; Spain.

Sumario: 1. África, continente emisor de inmigrantes. 2. La inmigración africana en España y su representación televisiva. 3. Metodología. 4. Frecuencia de aparición e importancia de los inmigrantes africanos en la televisión. 5. Falta de información personal y laboral. 6. Precariedad y vulnerabilidad. 7. Transgresión de las leyes, agresividad y relaciones poco confiadas. 8 . Conclusiones. 9. Referencias bibliográficas.

Summary: 1. Africa, a continent of immigrants issuer. 2. African immigration in Spain and their representation on television. 3. Methodology. 4. Frequency of occurrence and importance of African immigrants on TV. 5. Lack of information and work. 6. Precariousness and vulnerability. 7. Transgression of the laws, aggressive and confident relations shortly. 8 . Conclusions. 9. References.

\section{1. África, continente emisor de inmigrantes}

El acelerado crecimiento poblacional, la precaria situación económica y las deficientes condiciones de vida de la población de África la convierten en un continente predominantemente emisor de migrantes internacionales.

El Índice de Desarrollo Humano de los países africanos en promedio es, con diferencia, el más bajo respecto al resto de las regiones y al compararlo con el europeo resulta 1,66 veces inferior. Esto significa que su esperanza de vida, su educación y su PIB per cápita son peores que en los demás continentes. Otros indicadores de calidad de vida, como el acceso a fuentes de agua potable, corroboran que existen importantes razones para que un africano decida abandonar su tierra (ver Gráficos 1 y 2).

Los distintos conflictos armados y las situaciones de inestabilidad política han tenido graves repercusiones sobre las infraestructuras y sobre la oferta y demanda de servicios educativos y sanitarios en África. Ello se ha visto profundizado por las políticas de corte neoliberal aplicadas en las últimas dos décadas en diferentes países de ese continente, comandadas por instituciones financieras internacionales, que han supuesto recortes presupuestarios en estos sectores básicos (Bidaurratzaga Aurre, 2007). 


\section{Gráfico 1}

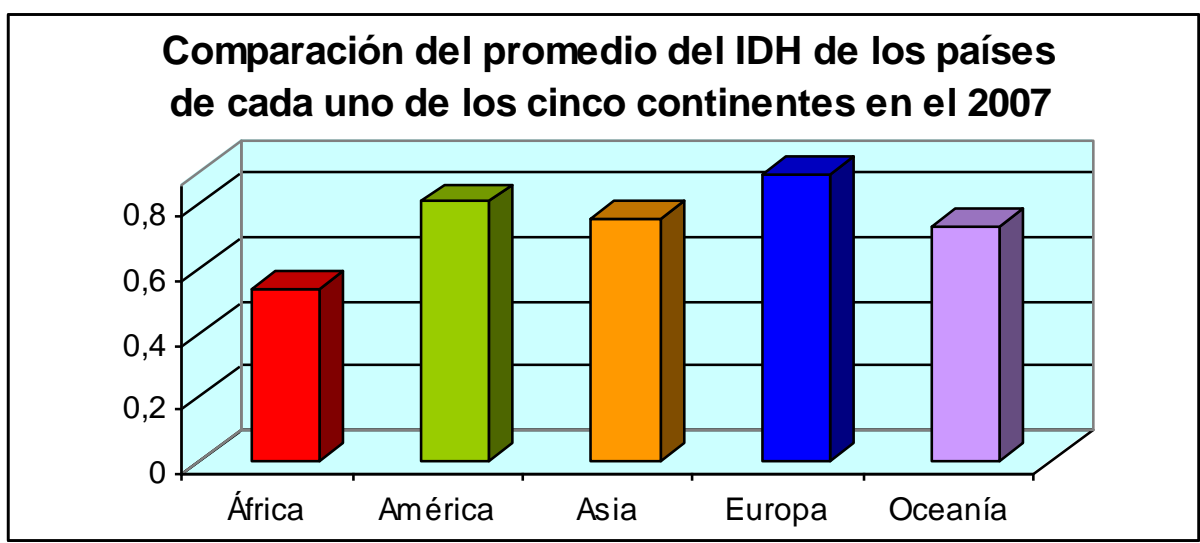

Fuente: Programa de las Naciones Unidas para el Desarrollo PNUD, 2007. Gráfico y cálculos de elaboración propia.

\section{Gráfico 2}

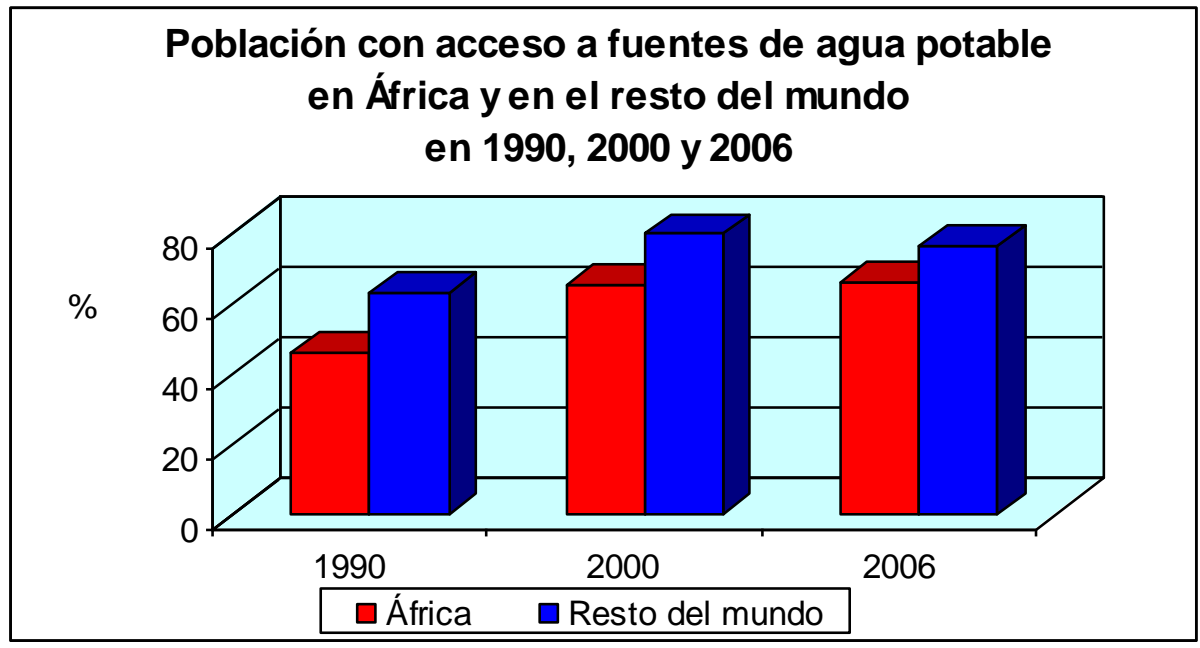

Fuente: INE, 2010a. Gráfico y cálculos de elaboración propia.

Por otro lado, la cifra de paro en África sigue aumentando, siendo la tasa de desempleo juvenil de casi un $30 \%$ y la de todas las personas en edad laboral mayor al 50\% (OIT, 2010). Mientras tanto, la población sigue creciendo a un ritmo superior que en las demás regiones (ver Gráfico 3), situación que profundiza la desigualdad con otras zonas del mundo y convierte a la emigración en una importante alternativa.

Según Guisán y Expósito (2001), el principal problema de África es su crecimiento poblacional, ya que su tasa media durante el siglo XX fue de 2,12\% anual, superando a la media mundial de $1,40 \%$. Como consecuencia, el desarrollo económico en términos de PIB ha sido escaso durante esa centuria, con un $1 \%$ anual, cifra que está por debajo de la media mundial y que representa la mitad de la tasa de crecimiento económico de Europa Occidental. 
Gráfico 3

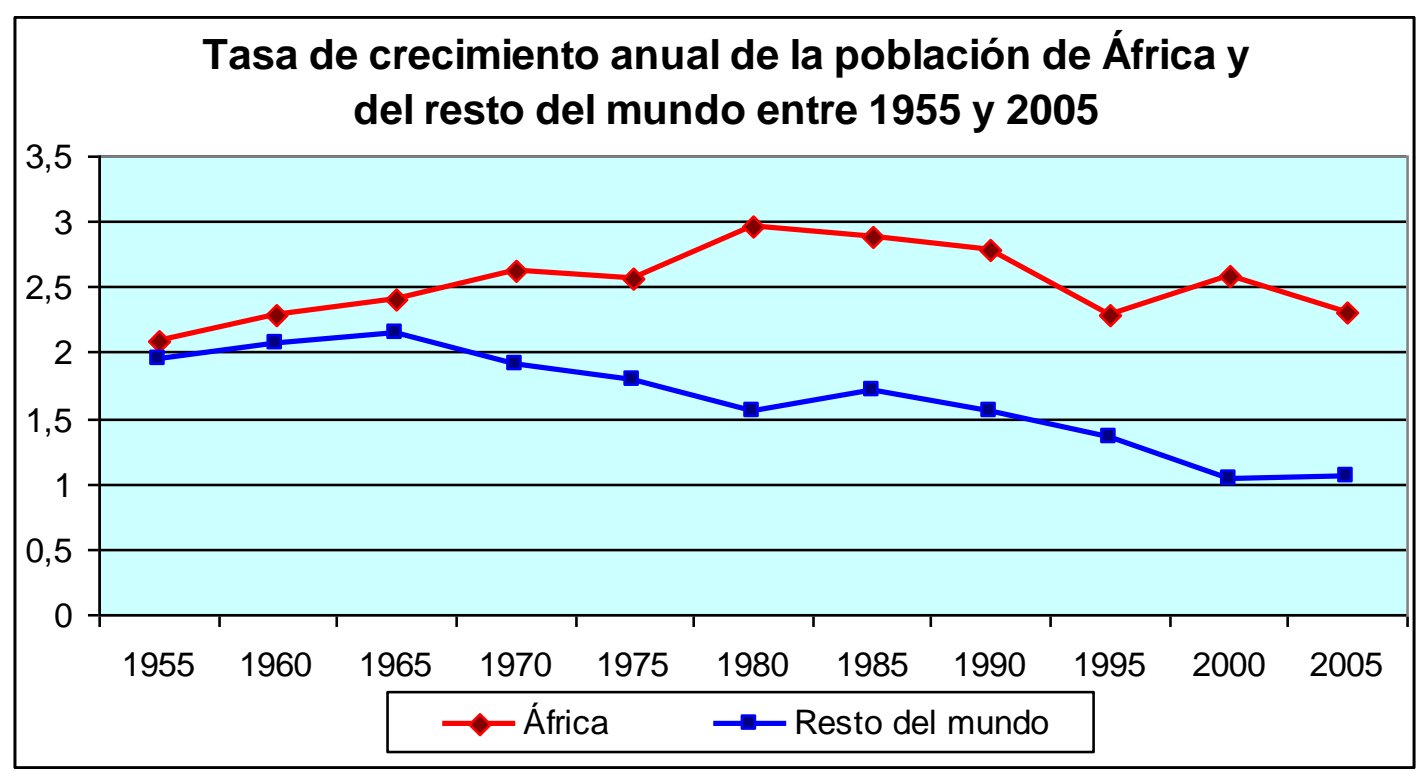

Fuente: INE, 2010a. Gráfico y cálculos de elaboración propia.

De este modo, el continente africano ha tenido un saldo migratorio predominantemente negativo, es decir, con mayor cantidad de emigrantes que de inmigrantes, desde mediados de la pasada centuria hasta los primeros años del presente siglo, como se puede apreciar en el siguiente gráfico.

\section{Gráfico 4}

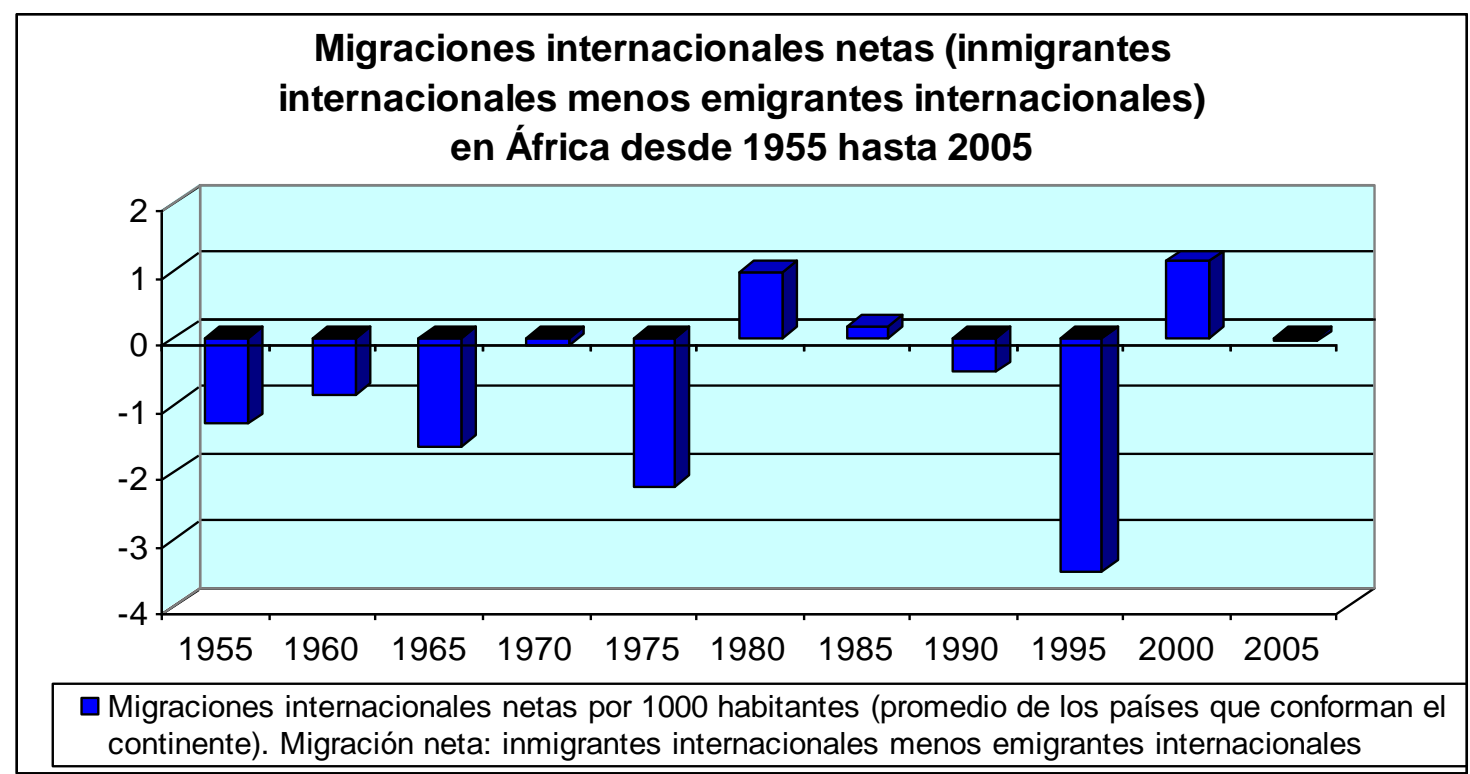

Fuente: INE, 2010a. Gráfico y cálculos de elaboración propia. 


\section{La inmigración africana en España y su representación televisiva}

En España residen actualmente 920299 inmigrantes de origen africano, que representan un $16,12 \%$ de la población nacida fuera de este país (INE, 2010b). No obstante, a pesar de no ser la comunidad de inmigrantes más numerosa, su llegada y permanencia se convirtió en un fenómeno de debate a comienzos del siglo XXI, debido al incremento de la llegada por vía marítima de un gran número de inmigrantes indocumentados a las costas canarias y andaluzas, principalmente provenientes de Marruecos y de África Subsahariana (Merino Arribas, 2008).

Aunque la mayoría de los inmigrantes, e incluso la mayor parte de los que no tienen autorización legal de residencia, llegan a través de puertos y aeropuertos, la inquietud de la ciudadanía especialmente en Canarias- se enfocó en las minorías llegadas en pateras o cayucos, a lo que contribuyeron las tragedias humanitarias que se derivaron de esta precaria forma de transporte y su consecuente repercusión mediática.

\section{Cuadro 1 \\ Número de inmigrantes de origen africano que arribaron las costas canarias desde 2002 hasta 2007 en pateras o cayucos}

\begin{tabular}{|c|c|c|c|c|c|c|}
\hline Año & $\mathbf{2 0 0 2}$ & $\mathbf{2 0 0 3}$ & $\mathbf{2 0 0 4}$ & $\mathbf{2 0 0 5}$ & $\mathbf{2 0 0 6}$ & $\mathbf{2 0 0 7}$ \\
\hline Número de inmigrantes & 9929 & 9555 & 8514 & 4751 & 31678 & 17038 \\
\hline $\begin{array}{c}\text { Variación porcentual respecto } \\
\text { al año anterior }\end{array}$ & & $-3,77$ & $-10,89$ & $-44,20$ & 566,76 & $-46,22$ \\
\hline
\end{tabular}

Fuente: CES, 2008. Cuadro y cálculos de elaboración propia.

El reduccionismo de los medios de comunicación al relacionar inmigración con llegada irregular de personas de otros países dio origen a diversos estudios sobre la manera como la prensa, la radio y la televisión abordaban este tema y sobre la imagen que ofrecían del colectivo inmigrante.

Además, la tardía y todavía débil preocupación por la integración de las personas de origen extranjero suscitó no solo la aplicación de políticas sociales, sino la preocupación por el inadecuado tratamiento de la información sobre inmigración en los medios. Las valoraciones que estos transmitían, al definir este fenómeno social como una amenaza y un problema, podían no estar contribuyendo a la incorporación armoniosa de los inmigrantes y a la apertura de los nativos para convivir sin prejuicios con ellos, condicionando incluso el fracaso de las políticas de integración. Esta inquietud ocasionó la elaboración, a instancias del Foro Canario de la Inmigración, de un decálogo para abordar el tema migratorio en la redacción de noticias, denominado "Por una comunicación integradora y no xenófoba" (Millet, 2007).

Esta situación también motivó la elaboración de estudios como el coordinado por Nicolás Lorite, que investigó los cambios sufridos en el tratamiento informativo de la inmigración en España, con datos recogidos en los años 1996, 2000 y 2002. Las conclusiones generales de esta investigación apuntaron que la manera en que los telediarios enfocan el tema de los inmigrantes ha cambiado: en 1996 existían pocas noticias sobre ellos, en el 2000 se hacía mucho énfasis en la cantidad de personas de origen extranjero que llegaban y en el 2002 comenzó a ganar peso informativo el tratamiento sobre los procesos de integración con sus variantes laborales y socioculturales, sin llegar a ser todavía el tema predominante (Lorite García, 2004). 
Más recientemente, Alberto Ardebol Abreu (2008) analizó todas las fotografías de inmigrantes publicadas en el año 2007 por los periódicos canarios El Día, Diario de Avisos, La Provincia y Canarias7 y concluyó que dichas fotos representaban casi siempre a africanos llegando irregularmente a las costas insulares. Además, se les identificaba con la debilidad, la carencia de iniciativa, la subalternidad y el delito. Primaba el retrato homogeneizador, en grupo, sobre el que busca la individualidad y la diferencia. Las acciones protagonizadas por este colectivo en las imágenes lo definen como dependiente e incapaz: en casi la mitad de las fotos de africanos aparecen siendo atendidos por los servicios de urgencia o rescatados por Salvamento Marítimo.

Por su parte, Raquel Rodríguez Díaz y Noemí Mena Montes (2008) investigaron sobre el tratamiento informativo de los periódicos El País y El Mundo durante la primavera de 2006, corroborando que existe una percepción problemática sobre la inmigración. Las historias sobre la situación dramática de algunos inmigrantes africanos fueron acompañadas, en algunos casos, de un lenguaje metafórico que sugería invasión, crisis y avalancha. Estos términos simplificados contribuyen a reforzar la idea de que el fenómeno migratorio es una amenaza para la sociedad española, especialmente para las regiones receptoras directas de este tipo de inmigración, como lo es Canarias.

Asimismo, la tesis doctoral de María Adoración Merino (2008), que analizó el contenido de los principales diarios regionales de esta comunidad autónoma para determinar las características de las noticias sobre inmigración ilegal africana entre 1999 y 2003, halló una carencia de campañas dirigidas a la ciudadanía para promover la acogida de inmigrantes, la presencia de editoriales xenófobos y racistas en El Día y Canarias7, la tendencia "integradora" de la mayoría de los mensajes que no fueran editoriales y la reproducción sin criterio de un discurso político que no ha estado a la altura de las circunstancias.

En el medio televisivo, destaca el estudio de Xavier Ruiz, Joan Ferrer, Matilde Obradors, Eva Pujadas y Oliver Pérez (2007), quienes analizaron los roles narrativos del inmigrante en la ficción televisiva española de producción propia. La recurrencia al engaño, la inadecuación de sus actos bienintencionados y la inutilidad de sus iniciativas fueron algunas de las características de las acciones estereotipadas y prototípicas de los inmigrantes. Por eso estos investigadores llegaron a la conclusión de que estos programas, aunque no alimenten directamente los valores más xenofóbicos y racistas, podrían estar promoviendo una actitud de desconfianza de la población autóctona ante el inmigrante pues suele ser ineficaz, poco preparado para conseguir los objetivos que se propone y tiende a utilizar la mentira. También obtuvieron un dato muy curioso: la inexistencia de magrebíes en las series españolas.

Otros estudios sobre la imagen de los inmigrantes en los medios de comunicación (Casero Ripollés, 2003; García Castaño, Granados Martínez y Capellán de Toro, 2003; Muñiz e Igartua, 2004; Galán Fajardo, 2006; Martínez Pastor y Vizcaíno-Laorga, 2008; Pablos Coello y Ardevol Abreu, 2008; Sabés Turmo, 2010, entre otros) parecen coincidir en que la inmigración es abordada principalmente como problema y como una amenaza, además de que se le relaciona con la delincuencia y otros problemas sociales. Otro resultado común en los estudios enfocados en el género informativo es que los inmigrantes más representados y también de los que se ofrece peor imagen son los africanos y los que tienen una situación administrativa irregular. Asimismo, en los estudios en los que se les pregunta a las personas de origen foráneo si están satisfechas con su representación en los medios, la respuesta suele ser negativa, manifestando este colectivo un descontento hacia esa imagen. 


\section{Metodología}

La investigación que dio origen a este artículo surgió también de la inquietud por el tratamiento que dan los medios de comunicación a la inmigración, especialmente por la imagen que transmiten de las personas de origen extranjero.

La fundamentación de este estudio se realiza desde las teorías de los efectos a largo plazo de los medios, que coinciden en atribuirle a la televisión, como medio de mayor audiencia y alcance, la capacidad de influir -lenta y acumulativamente- en la percepción de la realidad que tienen las audiencias. Las investigaciones de George Gerbner y la Escuela de Annenberg, la teoría de la espiral del silencio y la hipótesis de la función de establecer la agenda pública han comprobado que existe una estrecha vinculación entre los contenidos de este medio y la noción que sus públicos tienen del entorno.

Por su manera de "mostrar" lo alógeno más que por consejos directos, la televisión transmite valoraciones sobre la diversidad y a la vez enseña qué es confiable y enriquecedor, y qué es una amenaza o un problema. Si bien no es la única fuente desde la cual las personas extraen informaciones para construir su imagen de la realidad social, sus representaciones son ofrecidas como realidades objetivas y como si ese fuera el modo dominante y más extendido de concebir el mundo. Constituyen, además, el punto de referencia con el que se orientan personas de todas las clases sociales y son un horizonte común de conocimientos sobre el entorno.

Por esa capacidad de influencia de la televisión, que puede condicionar la apertura de la población autóctona para aceptar a las personas de origen extranjero, relacionarse con ellas y colaborar en su proceso de integración, resultaba de suma importancia determinar qué representaciones ofrece este medio del fenómeno de la inmigración y de los inmigrantes.

Para lograr este objetivo se utilizó la técnica del análisis de contenido, aplicada a la programación televisiva con mayor audiencia en Tenerife. La ficha de análisis se estructuró tomando en cuenta cada una de las dimensiones que describen las representaciones de los medios: lo que hay (cómo son los inmigrantes que aparecen en la TV), lo que es importante (qué aspectos de ellos y del fenómeno migratorio se enfatizan), la calificación valorativa de los elementos (qué juicios de valor se les atribuyen) y las tendencias de relación entre los elementos (con qué temas se les vincula).

Se partió de la hipótesis de que en la representación televisiva de los inmigrantes existían rasgos que correlacionaban con peores condiciones de vivienda, menor satisfacción con el trabajo, situación económica más precaria, y pocas o malas relaciones con la población autóctona, en otras palabras, con una peor integración a la sociedad receptora, y esos elementos eran: sexo femenino, origen étnico distinto al caucasoide, nacimiento en países subdesarrollados, ausencia de fama y haber emigrado por razones económicas o políticas. Asimismo, se planteó la hipótesis de que esos rasgos se relacionaban también con valoraciones más negativas en cuanto a capacidad de adaptación, compatibilidad cultural, actitudes, comportamientos y respeto de la ley de esos inmigrantes.

En este artículo se resumirán algunos de los resultados más importantes de esa investigación, referidos al colectivo inmigrante de origen africano, para comprobar o refutar la hipótesis sobre su situación de menor integración y de menor capacidad e intención de adaptación en su representación televisiva.

De comprobarse estas hipótesis, la televisión podría considerarse un factor favorecedor de la discriminación de los inmigrantes de origen africano, por contribuir a crear la noción de que su integración es más difícil y menos común y por transmitir una justificación de la exclusión de este grupo. 
El tamaño de la muestra analizada fue de 9595 minutos (159,9 horas) de programación. Este dato fue determinado a través de la fórmula para fijar el tamaño muestral en universos infinitos (de más de 100000 individuos, en este caso horas):

$$
\mathrm{n}=\mathrm{o} 2 \cdot \mathrm{p} \cdot \mathrm{q}
$$

E2

en la que ơ es el nivel de confianza, p y q las varianzas y E el error muestral (Sierra Bravo, 1999). Para este estudio el nivel de confianza fue de dos sigmas, la desviación típica se estableció en un $50 \%$ y el error muestral se estableció en un $8 \%$. Sustituyendo estos datos en la fórmula, se obtuvo un resultado de 156 horas, que finalmente se convirtieron en 159,9 horas, para no cortar el final de los últimos programas grabados.

Para elegir las horas de programación que conformaron la muestra primó el criterio de la audiencia de los programas. Se seleccionaron aquellos que eran sintonizados por mayor cantidad de personas según una medición facilitada por TNS. Se utilizó este criterio porque para el objetivo de la investigación tenían mucha mayor relevancia los programas más vistos, pues las nociones y representaciones de la realidad que estos transmiten son recibidas por más personas y por lo tanto mayor porcentaje de la población autóctona se verá influenciada por la imagen que estos reflejen sobre los inmigrantes.

Para que todos los días de la semana tuvieran la misma representación en la muestra, se dividieron las 159,9 horas que la conformaban entre 7 , resultando que a cada día de la semana correspondían unas 22,3 horas (1338 minutos) de grabación aproximadamente. Estas se completaron seleccionando en orden decreciente los programas según su audiencia media hasta llegar al tiempo total correspondiente a ese día de la semana. En cada grabación se incluyó la publicidad transmitida en los programas seleccionados. La grabación de la muestra se realizó desde el 30 de marzo hasta el 21 de mayo de 2008.

La decisión de no circunscribir la muestra a un solo género televisivo se debió a que para comprender mejor los mensajes de este medio no deben entenderse como programas inconexos, sino como un universo de global ideas y como un sistema de elementos coherentemente relacionados. La programación de ficción, entretenimiento y publicidad también transmite ideas sobre la realidad, no solo los informativos y programas de entrevistas. En todos los formatos se hallan las perspectivas de pensamiento, los valores, los puntos de vista y las normas de conducta que se transmiten a la audiencia (Gerbner, 1969)

La cadena de la que se analizaron más minutos fue Telecinco (3321 minutos), seguida a corta distancia por Antena3 (3040 minutos), y luego por Televisión Española (1581 minutos, menos de la mitad que Tele5), Cuatro (967 minutos), Televisión Canaria (732 minutos) y Televisión Española 2 (apenas 54 minutos). El género de mayor duración en la muestra fue la ficción, con un 45,9\% del tiempo muestral, seguido por el entretenimiento (34,4\%), por la información (18,6\%) y, por último, por la publicidad $(1,1 \%)$. Casi tres cuartas partes de la muestra fueron programas producidos en España, y casi un cuarto de esta fueron producciones estadounidenses.

La unidad de análisis que se seleccionó para este estudio fue la secuencia, definida como "aquel conjunto de acontecimientos que, aunque no se desarrollen todos en el mismo escenario, sí poseen una cierta unidad temática e incluso temporal" (Villafañe y Mínguez, 1996: 192). Se consideró la secuencia la unidad más apropiada para las características de la muestra por su facilidad de aplicación a todos los géneros televisivos y porque resultaba más práctica para la codificación de las distintas características que tiene la representación de los inmigrantes, ya que dentro de un mismo programa se podían ofrecer distintas representaciones, pero dentro de un segmento con unidad temática era más difícil que se ofrecieran nociones contradictorias del mismo. 
En este estudio se consideró inmigrante a cualquier persona nacida en el extranjero y/o cuya residencia regular estaba ubicada en el extranjero, que se traslada a otro país distinto para fijar allí su residencia. Asimismo, se definió inmigración como el fenómeno social que se refiere a la entrada en el país de personas que han nacido y/o proceden del extranjero.

Se registró en una ficha cada emisión analizada. Asimismo, se rellenó una ficha de análisis (conformada por 105 variables) por cada secuencia, es decir, por cada unidad de análisis, con la excepción de las secuencias en las que no se mencionaban, aparecían o actuaban inmigrantes, y en las que además no se mencionaba el tema de la inmigración, para las cuales se respondió una sola vez (por programa) la ficha. En total se analizaron 1109 unidades de análisis.

Una vez estudiada la muestra a través de la ficha de análisis, los datos obtenidos se importaron al programa SPSS (versión 13) para su tratamiento estadístico. En esta fase se compararon los resultados de cada una de las preguntas de la ficha por cada grupo de inmigrantes según género, continente de nacimiento, origen étnico, fama, razón principal de emigración y religión.

Para el análisis de los resultados de las distintas variables que conformaron la ficha de análisis predominó el tiempo total de duración de cada una de las categorías u opciones disponibles en cada variable, aunque también se tomó en cuenta la frecuencia de aparición de cada categoría (número de unidades de análisis en las que esa fuera seleccionada). La decisión de medir la frecuencia de las esta manera estuvo motivada por la disparidad de la duración de las distintas unidades de análisis (secuencias), que osciló desde 0,10 hasta 24,25 minutos, y por la inexactitud en la que se hubiera incurrido si se contaban las unidades de análisis y no los minutos que duraron.

Finalmente, se aplicó un contraste de diferencias muestrales de proporciones o diferencia de porcentajes, a fin de evaluar si existían discrepancias estadísticamente significativas entre el tiempo de duración de las distintas categorías de la ficha de análisis en cada uno de los grupos de inmigrantes estudiados (por sexo, continente de nacimiento, origen étnico, fama, principal razón de emigración, religión y similitud de sus expresiones culturales con las de la población autóctona). Según este estadístico, los valores de $p$ menores o iguales a 0,05 indican una diferencia estadísticamente significativa entre los pares evaluados (por ejemplo, diferencia entre inmigrantes africanos e inmigrantes europeos para los resultados de la categoría profesional), y los valores iguales o menores de 0,01 indican que esa diferencia es altamente significativa.

\section{Frecuencia de aparición e importancia de los inmigrantes africanos en la televisión}

De los 9595 minutos de programación televisiva analizados en esta investigación, en un 18,5\% (1773,25 minutos) aparecieron, actuaron o se mencionaron inmigrantes. Ese sector de la muestra, en el que figuraron personas de origen o procedencia extranjera, fue el que se utilizó para estudiar la imagen de los inmigrantes africanos, de modo que ese $18,5 \%$ se convierte, a efectos de estos resultados, en un $100 \%$.

La característica más relevante de la representación televisiva de los inmigrantes africanos fue su escasa frecuencia de aparición, mención o actuación. De los 1773,25 minutos en los que figuraron inmigrantes en la muestra analizada, solo 107,95 correspondieron a personas nacidas en este continente o procedentes de él, lo que representa apenas un 6,09\%.

Los inmigrantes que procedían de Europa comunitaria fueron los más representados de la muestra $(29,78 \%)$, mientras que la suma del tiempo en que figuraron africanos, asiáticos, 
europeos no comunitarios y oceánicos no llegó a un 15\%. Sin embargo, los datos oficiales del año de recogida de la muestra (2008) indican que solo el primer grupo (africanos) representaba en realidad un 15,79\% de la población de origen extranjero en España (INE, 2010b) y, si se suman los porcentajes de todos estos grupos, representaban un 25,14\%. En sentido contrario, los norteamericanos, que figuraron en la muestra en un 15,05\% (del tiempo total con inmigrantes), solo significaban un $1,36 \%$ de la población de origen extranjero en España.

Asimismo, en la programación televisiva estudiada se pudo constatar que los inmigrantes que nacieron o procedían de países desarrollados tuvieron en la muestra estudiada un 7,32\% más de representación que los que nacieron o procedían de países subdesarrollados, cuando en la realidad son mayores las entradas de personas que provienen de países pobres y con escaso desarrollo.

A esta representación sesgada de la realidad que hace la televisión George Gerbner la denominó "demografía perversa" y demostró empíricamente que la aparición más frecuente de algunos grupos ocasionaba que las personas que utilizaban este medio con mayor asiduidad llegaran a pensar que la sociedad está realmente compuesta en mayor proporción por dichos colectivos. En lo que respecta a los inmigrantes africanos, su poco frecuente representación televisiva podría no favorecer a que los nativos vean con naturalidad su presencia en la sociedad española, y que lleguen a creer que son un grupo más minoritario de lo que realmente son.

Por otro lado, la teoría de la función de establecer la agenda planteaba que los medios influyen en la selección de los temas que son prioridad en el ámbito público (e incluso privado). Por ello, el que en la televisión aparezcan, se mencionen o actúen durante menos tiempo inmigrantes africanos podría contribuir a que su integración no fuera un tema de especial interés ni prioridad, lo que redundaría en una menor participación de la población autóctona en la discusión y el debate de las acciones normativas y coercitivas hacia ellos.

\section{Gráfico 5}

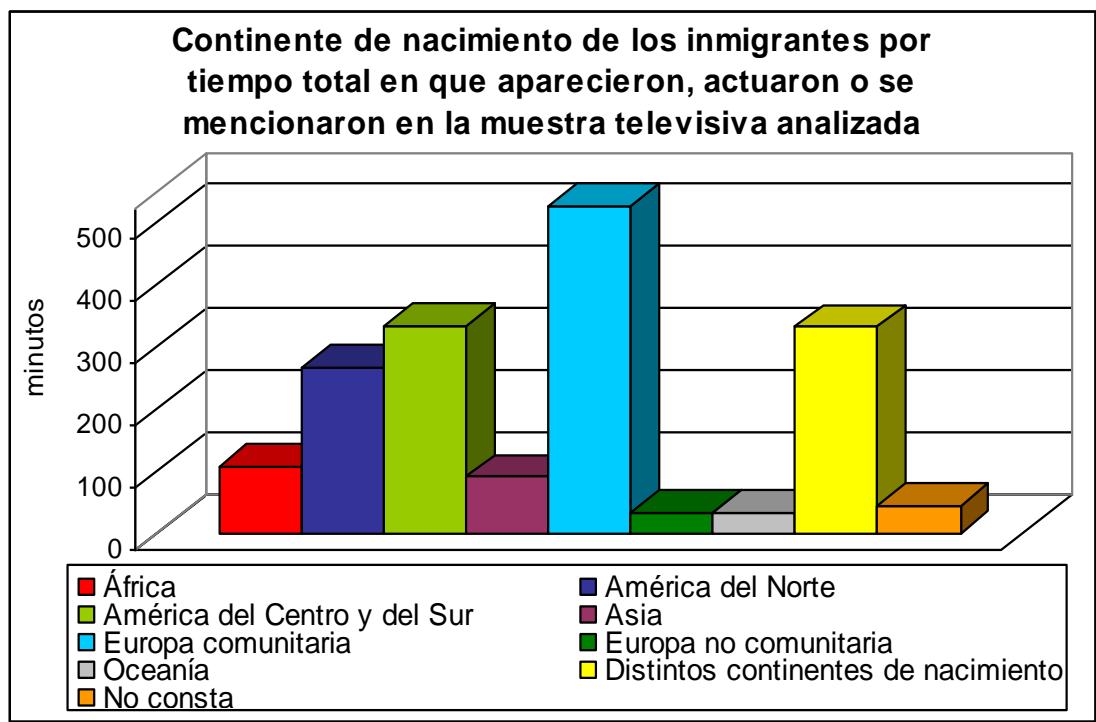




\section{Gráfico 6}

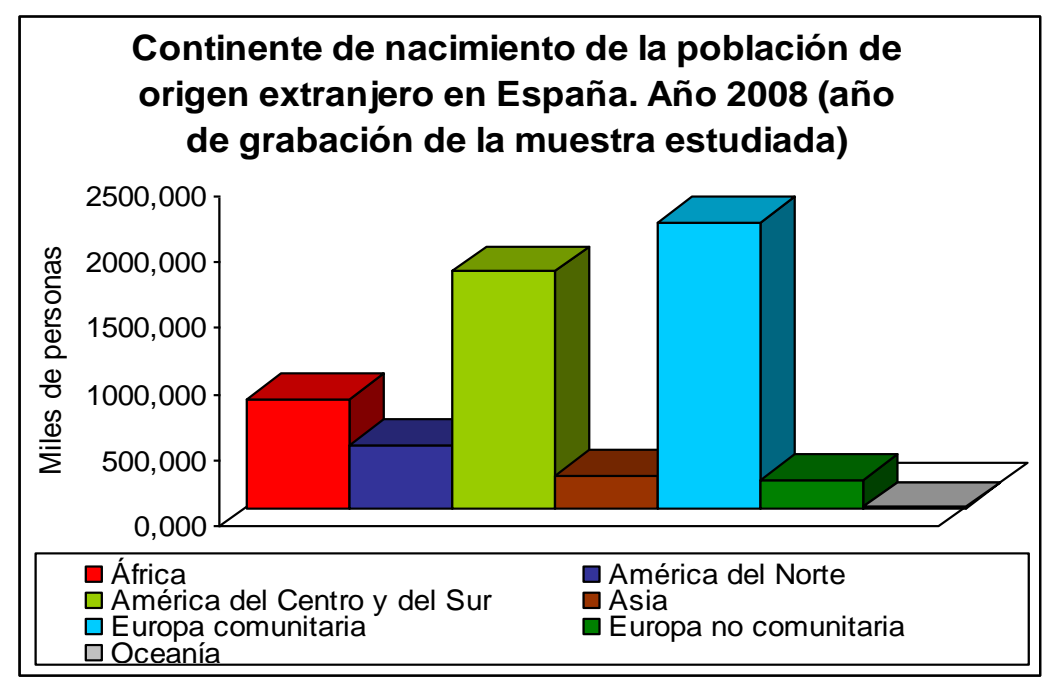

Este resultado fue distinto al obtenido por García Castaño, Granados Martínez y Capellán de Toro (2003) en su estudio del tratamiento informativo de la inmigración en la radio, la televisión y la prensa andaluces, en el cual concluyeron que los inmigrantes de origen marroquí, árabe o africano fueron los más representados. Tampoco coincidieron con los resultados de Muñiz e Igartua (2004), quienes en su análisis de contenido de los diarios nacionales y de los informativos de las cadenas estatales observaron que predominaban las personas procedentes del continente africano, con un 40,9\%, mientras que las de países latinoamericanos, europeos del Este y asiáticos aparecían menos.

Estas diferencias podrían explicarse, primero, por el hecho de que estos estudios se limitaron al género informativo, mientras que la presente investigación incluyó a todos los géneros. En segundo lugar, por el concepto de inmigrante utilizado en este estudio, que incluye a las personas procedentes del Espacio de Schengen que se trasladan a cualquier país europeo comunitario, quienes en el marco conceptual de la Unión Europea no son definidos como inmigrantes.

Otro aspecto importante de la frecuencia de aparición de los inmigrantes africanos en televisión fue la total ausencia de este colectivo en el género ficción y su más frecuente representación en los géneros de información y entretenimiento (principalmente magacines). 


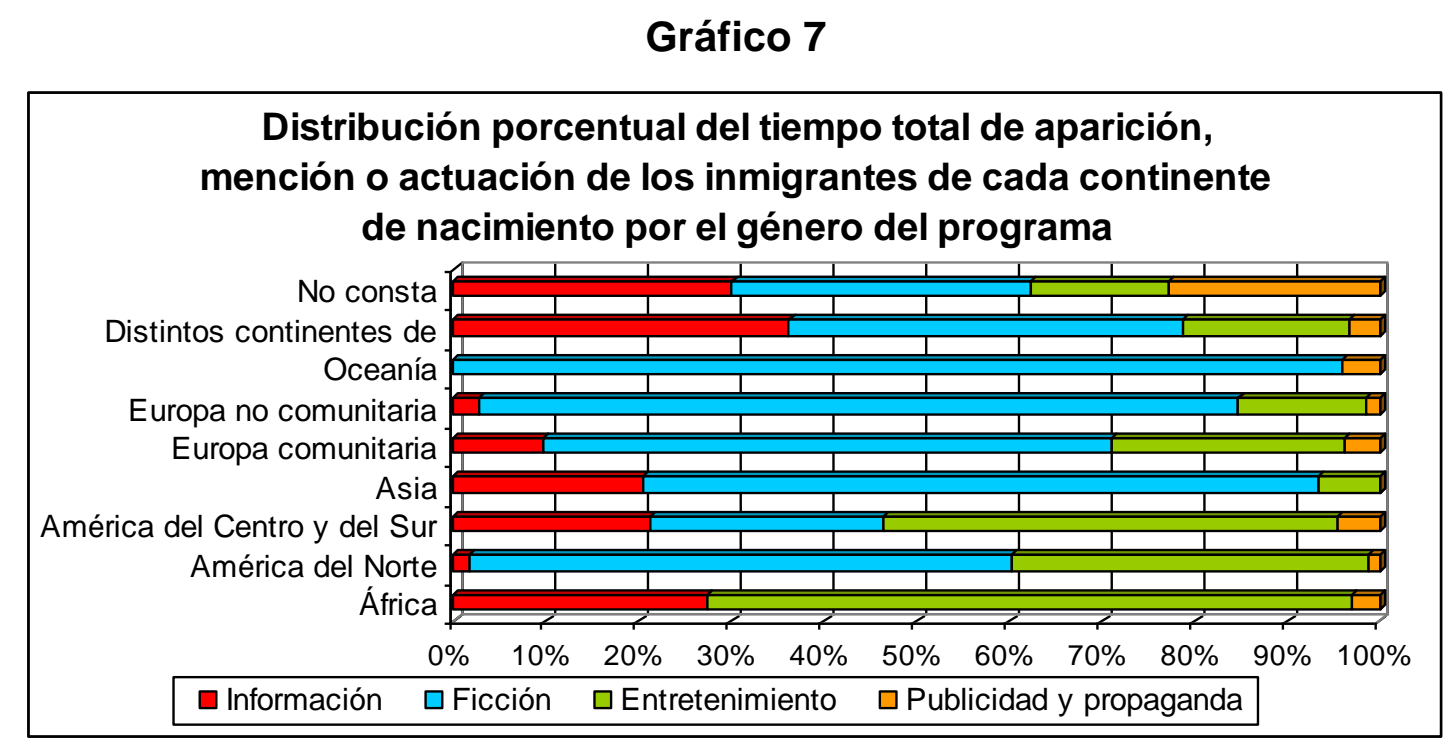

Los inmigrantes africanos fueron los que más frecuentemente desempeñaron el rol de invitados, entrevistados o sujetos de una noticia en magacines y, después de los grupos de inmigrantes con distintos continentes de nacimiento y de los que no se conoce su lugar de origen, fueron los que durante mayor porcentaje de tiempo ejercieron el papel de sujetos de una noticia en un telediario, conformando estos dos roles un $\mathbf{8 6 , 8 0 \%}$ del tiempo total en que figuraron personas nacidas en este continente. En el primer rol se diferenciaron de forma altamente significativa con todos los demás grupos, menos con los asiáticos, los oceánicos (que nunca desempeñaron participaron en magacines) y los europeos no comunitarios. $Y$ en el segundo, tuvieron diferencias altamente relevantes con los nacidos en Europa comunitaria $(p=0,0000)$.

La ausencia de inmigrantes africanos en los programas de ficción coincidió con los resultados obtenidos por Ruiz, Ferrer, Obradors, Pujadas y Pérez (2007), en los que detectaron la inexistencia de magrebíes en las series de manufactura española. Esta "omisión" determina la menor aparición de los inmigrantes en situaciones de cotidianidad y normalidad en la sociedad receptora, pues siendo personajes de ficción formarían parte de una historia y se darían a conocer más aspectos personales de ellos, ya fuera de forma sesgada o coherente con la realidad.

Por el contrario, el mayor desempeño del rol de sujeto de noticias en los informativos vincula la imagen de los inmigrantes africanos con la ocurrencia de un hecho noticioso, por lo general negativo. De hecho, en un $73,05 \%$ del tiempo en que figuraron personas nacidas en África en los telediarios de la muestra lo hicieron en la sección de sucesos, que aborda noticias sobre tragedias humanitarias, desastres naturales, crímenes y todo tipo de transgresiones de la ley, de los que fueron víctimas o victimarios. 


\section{Gráfico 8}

Distribución porcentual del tiempo total en el que
aparecieron, se mencionaron o actuaron inmigrantes de cada
Continente de nacimiento por el rol que desempenaron
No consta
Distintos continentes de nacimiento
Oceanía
Europa no comunitaria
Europa comunitaria
Asia
América del Centro y del Sur
América del Norte
África

\section{Gráfico 9}

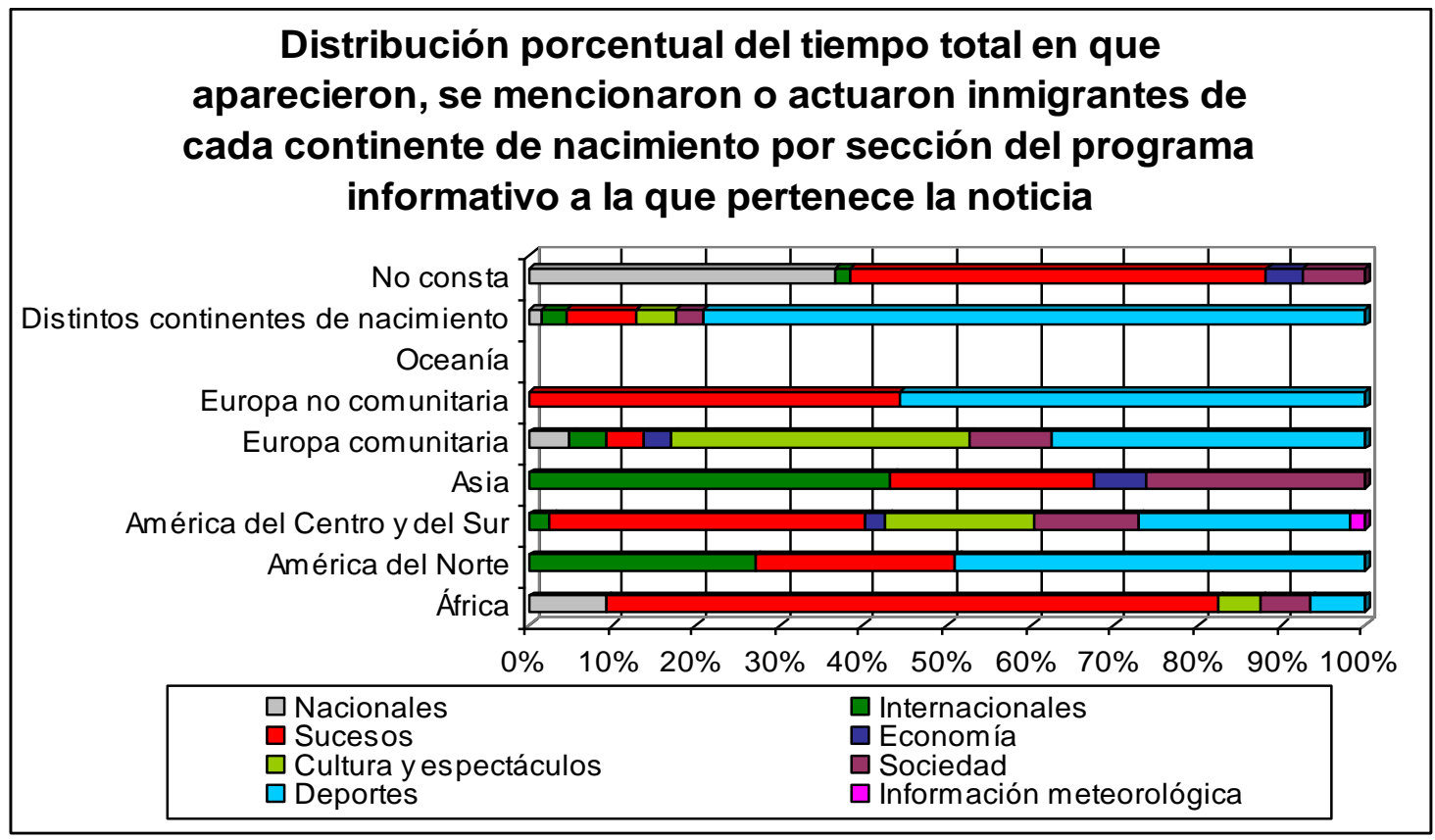


Otro factor que corroboró la menor visibilidad de los inmigrantes africanos fue que casi la mitad del tiempo en que aparecieron o se mencionaron estos (47,06\%) fueron figuras públicas o famosos, siendo el grupo según lugar de nacimiento en el que este porcentaje fue mayor (ver Gráfico 10), con diferencias significativas en la categoría "No es famoso" con el resto de los grupos, a excepción de los norteamericanos y de los grupos con distintos continentes de origen. Por esta razón, los inmigrantes africanos que no eran figuras públicas apenas aparecieron unos 55,65 minutos de la muestra estudiada (3,14\% del tiempo en que figuraron inmigrantes) y, de ellos, casi la mitad (26,35 minutos) correspondieron a programas informativos.

De modo que la imagen de africanos comunes, que trasladan de país su residencia para mejorar sus condiciones de vida, y que comparten cotidianamente en situación de normalidad con la población autóctona, fue casi inexistente. Se vinculó, por el contrario, la imagen de este colectivo con sucesos extraordinarios principalmente negativos, o con personas del mundo del espectáculo, del deporte de elite o del "corazón", cuyo proceso de integración suele ser menos complicado que el del resto de los inmigrantes.

\section{Gráfico 10}

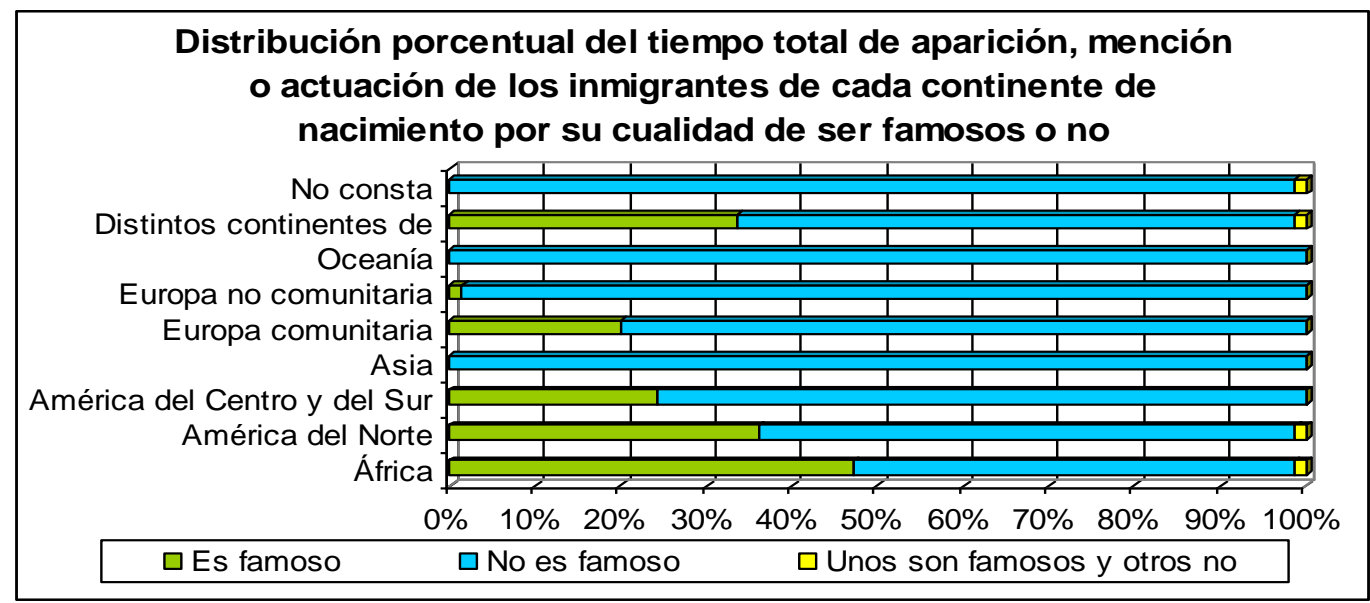

\section{Falta de información personal y laboral}

La poca visibilidad de los inmigrantes africanos en la muestra estudiada se vio reforzada por la falta de información que se ofreció de ellos, lo que fue constatado por los altos porcentajes de tiempo en que fue seleccionada la categoría No consta en variables relacionadas con sus características personales y laborales (ver Gráfico 11).

La hipótesis de la función de los medios de establecer la agenda, así como los estudios de George Gerbner y la Escuela de Annenberg, han destacado la capacidad de la televisión para influir en la importancia que la audiencia otorga a determinado tema. De modo que esta "omisión" de las principales características personales y laborales de los africanos, podría estar contribuyendo a que la población autóctona atribuya poca valoración al conocimiento de estos inmigrantes. Tampoco promueve la relación social cotidiana de estas con los africanos, porque no transmite la noción de que pueden ser similares a ellas en sus luchas, sentimientos, problemas y alegrías; en otras palabras, que el inmigrante nacido en ese continente puede ser "uno más" de la sociedad, en lugar de algo ajeno y desconocido. 
La investigación de Merino Arribas (2008) acerca de los mensajes sobre la inmigración irregular africana publicados en la prensa de Canarias entre 1999 y 2003 obtuvo un resultado similar: se encontraron escasas informaciones acerca de la vivienda, la escolarización o la inserción laboral de estos inmigrantes.

En la muestra analizada solo se obtuvo información sobre las razones por las que salieron de sus países los africanos y sobre el tiempo que planeaban permanecer en la sociedad receptora en un $14,31 \%$ y $20,89 \%$ respectivamente. El interés por conocer las razones de emigración es, sin embargo, fundamental para la comprensión del fenómeno migratorio y para evitar manipulaciones políticas que instrumentalizan dicho fenómeno con fines electorales.

De su nivel académico no se obtuvo ninguna información y de su situación económica, en comparación con la de la población autóctona, apenas un 15,1\%. En otros datos personales, como por ejemplo el estado civil y el número de hijos, se ofreció información en más de la mitad del tiempo que figuraron inmigrantes africanos, pero el porcentaje de la categoría No consta fue también elevado $(39,51 \%$ y $39,6 \%$ respectivamente), siendo el cuarto más alto de todos los grupos según continente de nacimiento. 


\section{Gráfico 11}

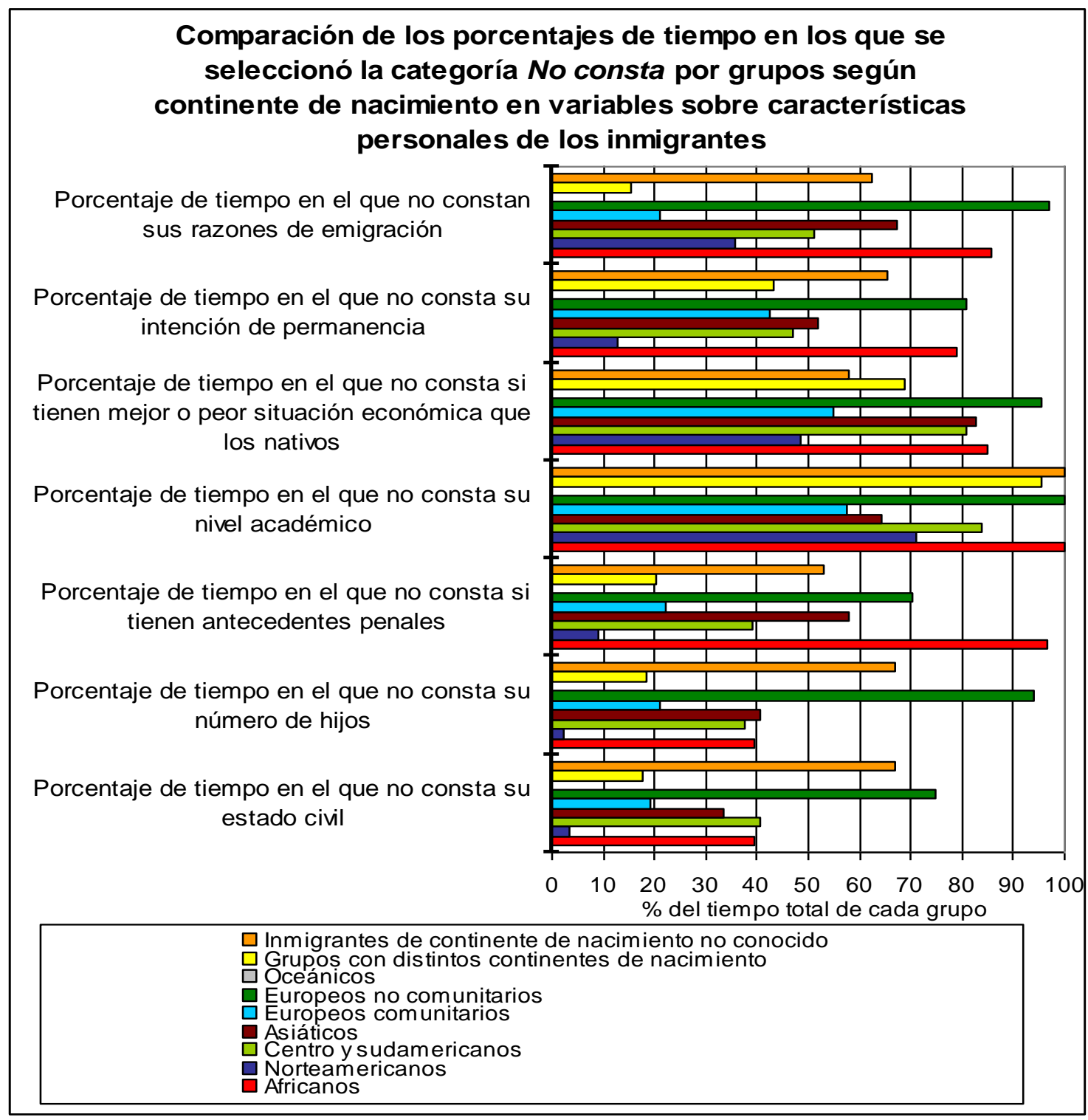

Respecto a las variables sobre las condiciones laborales de los inmigrantes, los africanos obtuvieron el más alto porcentaje en la categoría No consta en las variables correspondientes a la pertenencia de sus trabajos a la economía formal o informal, al grado de autonomía de sus actividades laborales y a sus categorías profesionales. Y obtuvieron el segundo porcentaje más alto de esa misma categoría en la variable que comparaba su categoría profesional con la de la población autóctona, y en la que determinaba el grado de adecuación de su trabajo a su capacitación. Igualmente, de los inmigrantes africanos fue de los que se supo en menor proporción de tiempo cuál era su principal ocupación y cuál su fuente principal de sustento (apenas en un $38,35 \%$ y $37,98 \%$ del tiempo total de este grupo). 


\section{Gráfico 12}

\section{Comparación de los porcentajes de tiempo en los que se seleccionó la categoría No consta por grupos según continente de nacimiento en variables sobre características laborales y económicas de los inmigrantes}

Porcentaje de tiempo en el que no consta si sus trabajos son adecuados a su capacitación

Porcentaje de tiempo en el que no consta si su categoría profesional es similar o diferente a la de los nativos

Porcentaje de tiempo en el que no consta su categoría profesional

Porcentaje de tiempo en el que no consta si trabajan por cuenta propia o ajena

Porcentaje de tiempo en el que no consta si tienen un trabajo en la economía formal o en la informal

Porcentaje de tiempo en el que no consta cuál es su principal fuente de ingresos

Porcentaje de tiempo en el que no consta cuál es su principal ocupación

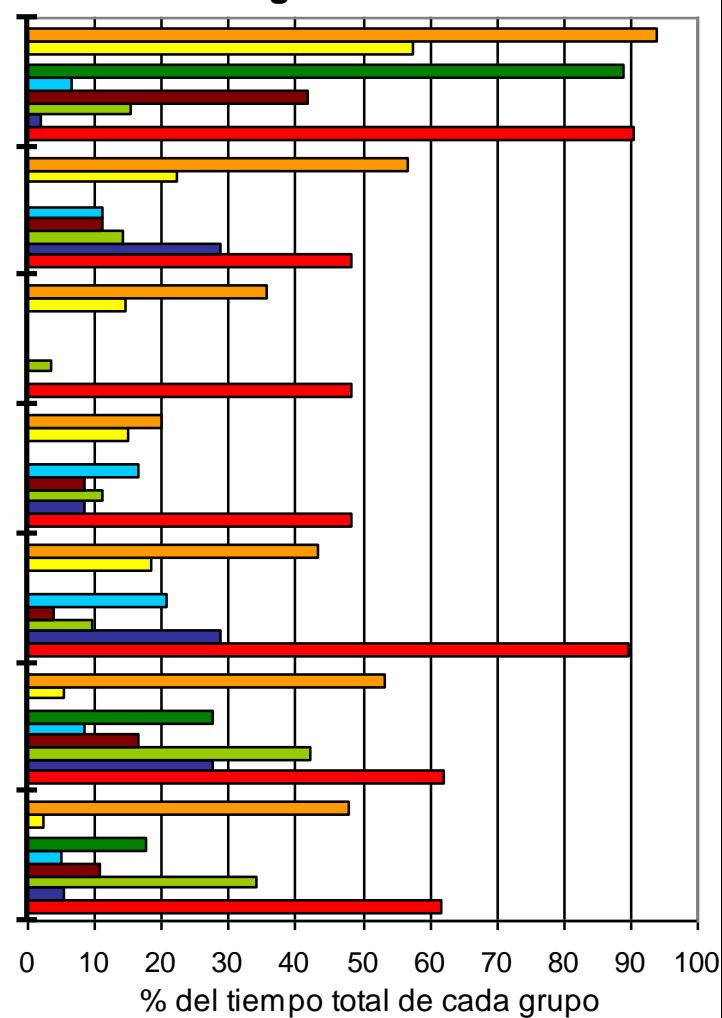

$\square$ Inmigrantes de continente de nacimiento no conocido

Grupos con distintos continentes de nacimiento

$\square$ Oceánicos

Europeos no comunitarios

Europeos comunitarios

- Asiáticos

$\square$ Centro y sudamericanos

Norteamericanos

$\square$ Africanos

De igual forma, los africanos fueron el primer grupo del que menos información se proporcionó acerca de su participación en acciones asociativas o políticas (96,62\% en la categoría No consta), el segundo en la similitud o diferencia de sus expresiones culturales respecto a las de la población autóctona $(20,19 \%)$ y el tercero en la religión a la que pertenecen $(97,31 \%)$.

Estos datos sugieren que existen grupos de inmigrantes -como los europeos comunitarios y los norteamericanos- en los que importan más sus características personales, laborales, culturales, políticas y económicas que en otros, como los africanos, en los que a estos aspectos se les atribuye poca importancia. Esta condición se une a su ya mermada visibilidad y a otras características que los representan con una acusada desigualdad respecto a la población autóctona, como se comprobará en el siguiente epígrafe. 


\section{Precariedad y vulnerabilidad}

La premisa básica de todos los indicadores de la integración de los inmigrantes es la paridad de estos respecto a la población autóctona. Muchos estudiosos de este tema (Aparicio, Tornos y Labrador, 1999; Torres, 2002; Musterd, 2003; García Añon, 2003; y Pajares, 2005, entre otros) coinciden en otorgarle a la igualdad legal la máxima prioridad en cuanto a integración se refiere. De modo que la situación administrativa irregular, que priva a las personas de origen extranjero de muchos derechos y oportunidades de los que disfrutan los nativos, está entre las primeras condiciones necesarias para que el proceso de adaptación a la sociedad receptora pueda comenzar.

Aunque solo en un $11,72 \%$ del tiempo en que figuraron inmigrantes africanos estos carecían de autorización legal de residencia, fueron el grupo por continente de nacimiento que obtuvo mayor porcentaje en esta categoría. Además, si solo se toman en cuenta los no famosos, el porcentaje de los que no tenían papeles subió a $22,73 \%$ y, en un $84,90 \%$ de todos los minutos en los que aparecieron, se mencionaron o actuaron personas de origen o procedencia foránea en situación administrativa irregular, estos eran nacidos en África. Este resultado coincide con los estudios de Ardebol Abreu (2008), Rodríguez Díaz y Mena Montes (2008) y Sabés Turmo (2010), en los que se vinculó acceso ilegal a inmigrantes africanos, aunque en la presente investigación la incidencia de este tópico fue mucho menor.

De forma más notoria, los africanos fueron representados con algunas características que indicaban precariedad laboral y tuvieron una mayor tendencia que los demás grupos a desempeñar el rol de víctimas o a tener condiciones de especial vulnerabilidad, indefensión o dependencia, tanto por la mayor proporción de tiempo en que se mostraron incapaces de resolver por sí mismos sus problemas, como por su recurrencia a ayudas gubernamentales y no gubernamentales.

Los africanos, junto a los europeos no comunitarios y a los inmigrantes de continente de nacimiento desconocido, fueron los grupos de los que menos se destacó su desempeño laboral cuando figuraron en la muestra estudiada. Obtuvieron los más bajos porcentajes de tiempo en las categorías correspondientes al desarrollo de actividades relacionadas con el trabajo, la descripción con imágenes y sonidos esas actividades, el mantenimiento de relaciones laborales con los nativos y la sustentación económica a través de sus trabajos, como se aprecia en el Gráfico 13. En estas categorías este grupo tuvo diferencias significativas principalmente con los nacidos en Oceanía, que fueron los que en mayor porcentaje de tiempo se dedicaron a trabajar. 


\section{Gráfico 13}

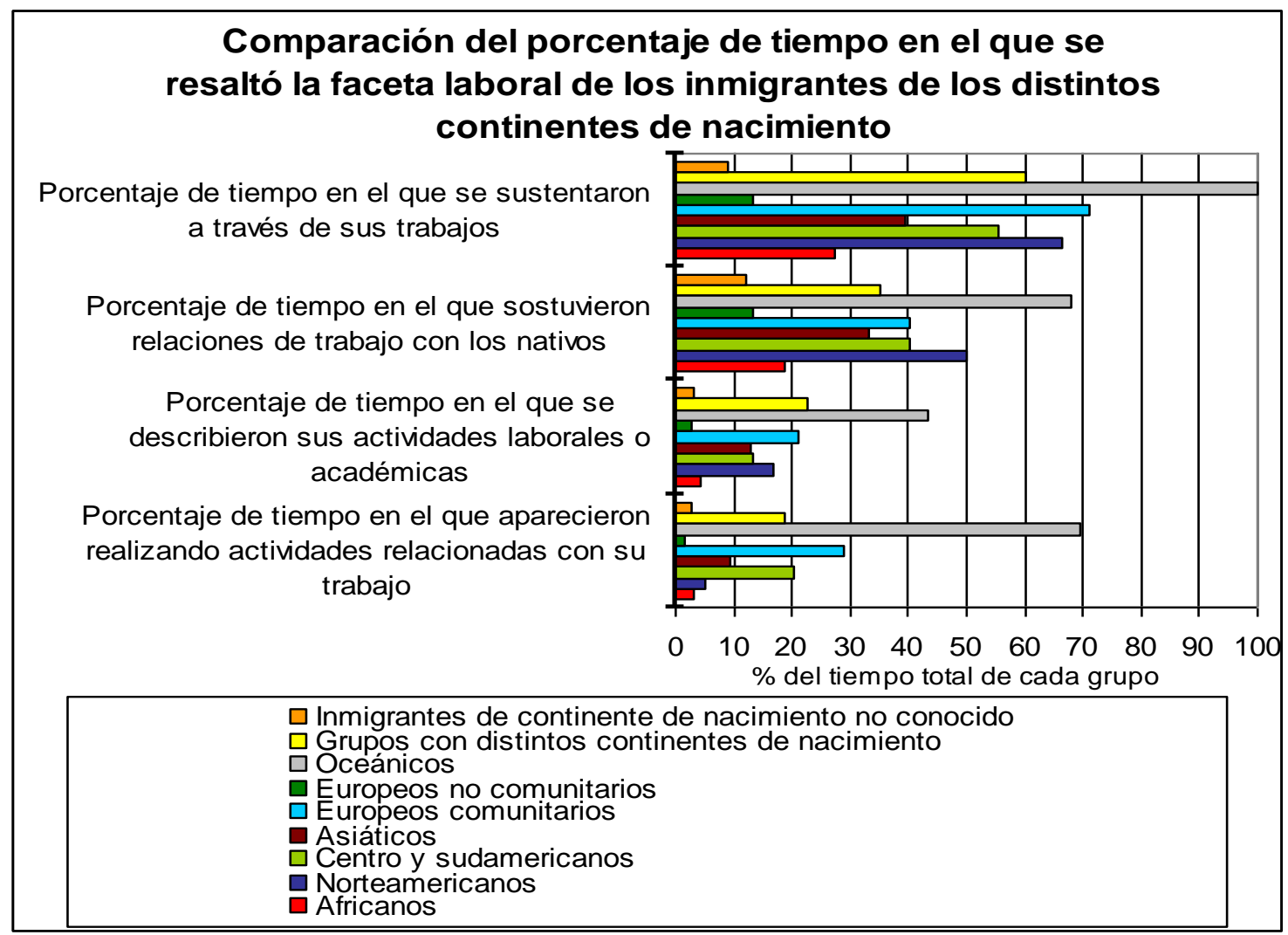

Del escaso tiempo que figuraron africanos que trabajaban (27,19\% del tiempo total de este grupo), apenas un $10,53 \%$ lo hacía con contrato y con cotización en la Seguridad Social. En términos absolutos fueron solo 3,45 minutos, lo que produjo que en esa categoría (Economía formal) este grupo tuviera diferencias estadísticamente significativas con los demás, a excepción de los europeos comunitarios y no comunitarios, y los de continente de nacimiento desconocido.

De igual forma, los nacidos en África fueron los inmigrantes trabajadores con más bajas categorías profesionales, además de tener el menor porcentaje de información disponible para esta variable $(51,76 \%)$. La categoría profesional en la que se desempeñaron durante mayor proporción de minutos fue Trabajadores cualificados en la agricultura y la pesca, con un 29,77\%, y luego Operadores de instalaciones y maquinaria, y montadores, con un 2,05\%.

Los inmigrantes trabajadores de origen africano apenas fueron representados un $9,62 \%$ de su tiempo total con empleos en las cuatro primeras categorías profesionales (Fuerzas Armadas; Dirección de las empresas y de las Administraciones Públicas; Técnicos y profesionales científicos e intelectuales y Técnicos y profesionales de apoyo). Ese mismo indicador, en los nacidos en Oceanía, Europa comunitaria y Norteamérica fue de 100\%, 76,80\% y 68,62\%.

Además, los africanos que se dedicaban a trabajar también fueron, junto a los europeos no comunitarios y los asiáticos, los que durante menor cantidad de tiempo fueron representados en trabajos adecuados a su capacitación. En esta categoría tuvieron diferencias significativas con los norteamericanos $(p=0,0000)$, los oceánicos $(p=0,0000)$ y los centro y sudamericanos $(p=0,0098)$. 


\section{Gráfico 14}

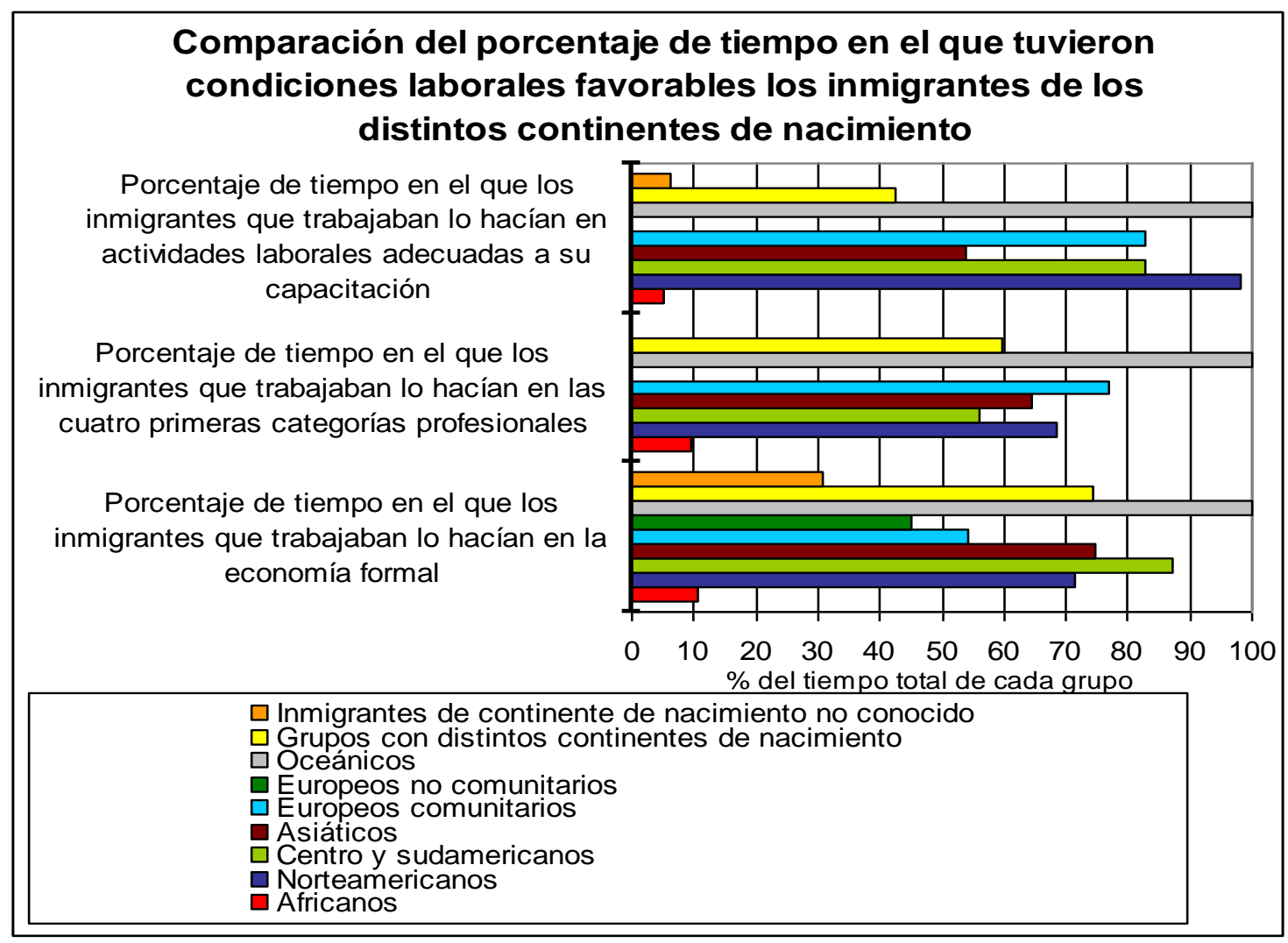

Este perfil del trabajador nacido en África complementa la imagen poco vinculada a las actividades laborales que tuvieron estos inmigrantes en la muestra estudiada, y configura uno de los rasgos más característicos de su representación televisiva: la precariedad de su situación.

Por otra parte, es una opinión más o menos generalizada que la principal contribución de los inmigrantes a la sociedad es su trabajo. En el último estudio del CIS (2008) sobre las actitudes ante la inmigración se obtuvo que casi la mitad de los españoles encuestados consideran conveniente regularizar la situación de una persona de nacionalidad extranjera sin permiso de residencia solo si en ese momento tiene un empleo, y el segundo motivo seleccionado con más frecuencia para permitir que los inmigrantes se queden en el país es que tengan una cualificación laboral de las que España necesita.

Si la valoración que actualmente la población española hace de lo necesaria o útil que es la presencia de los inmigrantes depende en gran medida de su situación laboral, la imagen desvinculada del trabajo que la televisión emite de los nacidos en África podría no favorecer que los nativos consideren conveniente su presencia y permanencia en la sociedad.

Igualmente, su precaria situación laboral podría estar favoreciendo la idea de que esa es su posición habitual en la estructura socioeconómica de la sociedad receptora, lo cual podría contribuir a que la población autóctona no asuma una postura contraria a la desigualdad de oportunidades de determinados grupos de inmigrantes, sino que la vea como algo normal.

Pero la precariedad de los africanos no se limita al ámbito laboral, los nacidos en ese continente también lideraron el grupo de los que vivían de ayudas gubernamentales, obteniendo un $3,71 \%$ en 
esa categoría, y ocuparon el segundo lugar de los que requieren de ayudas no oficiales para subsistir (1,39\%), después de los asiáticos (11,10\%).

Asimismo, a pesar de la escasa información que en general se obtuvo acerca de la vivienda los inmigrantes, del tiempo en que estos fueron representados habitando un centro de acogida, un $60,61 \%$ eran africanos.

En el mismo sentido, los inmigrantes nacidos en ese continente se destacaron por la elevada proporción de tiempo en la que desempeñaron el rol de víctimas: un $41,45 \%$ de su tiempo total de aparición, mención o actuación. Se ha definido como víctima un individuo que ha sufrido un perjuicio material, físico o moral por actuaciones de otras personas con las que tiene relación. En esta categoría, este grupo tuvo diferencias significativas con los de distintos continentes de nacimiento $(p=0,0024)$, con los europeos comunitarios $(p=0,0021)$ y con los centro y sudamericanos $(p=0,0072)$, por ser estos tres los que obtuvieron porcentajes más bajos, $y$ distintos a cero.

La autonomía o independencia, definida como la capacidad de los inmigrantes para resolver problemas cotidianos por sí mismos, fue una característica que estuvo presente en los africanos (junto con los centro y sudamericanos y los de continente de nacimiento desconocido) en menor proporción que en los demás grupos: apenas en un 62,48\% del tiempo total en que aparecieron, se mencionaron o actuaron. En esta categoría tuvieron diferencias significativas con los nacidos en América del Norte $(p=0,0000)$, Europa comunitaria $(p=0,0000)$, Europa no comunitaria $(p=0,0137)$, Oceanía $(p=0,0004)$ y distintos continentes $(p=0,0000)$.

Esta representación de precariedad, vulnerabilidad, falta de autonomía y tendencia a desempeñar el rol de víctimas podría no contribuir a que la población autóctona favorezca la incorporación de estos inmigrantes en la estructura socioeconómica en igualdad de condiciones, porque la imagen que se ofrece de ellos (y que por ser pública y presentada como si fuera objetiva puede influir en la idea de realidad que se hagan los telespectadores) sugiere cierta inferioridad, cierta incapacidad para poder ocupar puestos de responsabilidad en el sistema productivo del país y para hacer aportes a la sociedad receptora en lugar de demandar continuamente recursos de ella.

La imagen de dependencia podría transmitirle a la población autóctona la idea de que estos inmigrantes requieren una protección paternalista, y esto podría generar rechazo hacia ellos, por el hecho de percibirlos más como consumidores de (y por ello competidores por) los recursos públicos, que como ciudadanos trabajadores y productivos. Este rechazo, a su vez, podría originar acciones de discriminación, exclusión y desigualdad en el trabajo, en el acceso a la vivienda, a los servicios públicos, etc. 


\section{Gráfico 15}

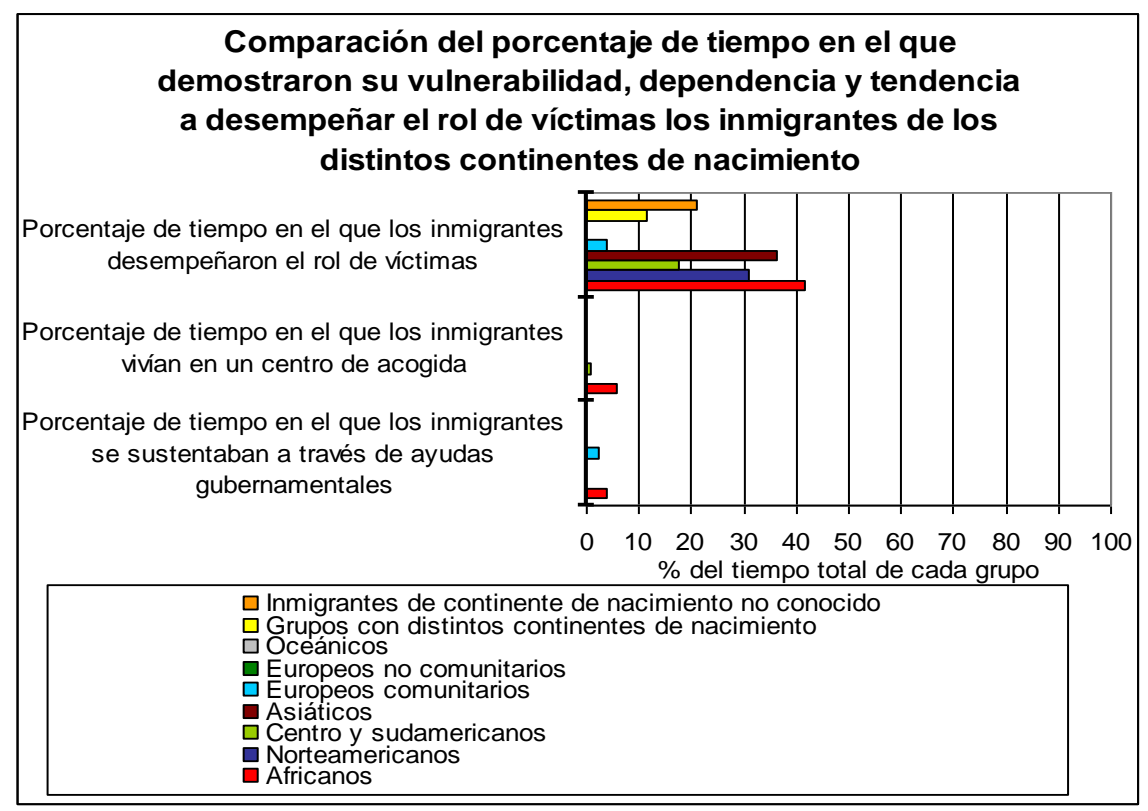

\section{Transgresión de las leyes, agresividad y relaciones poco confiadas}

Los inmigrantes africanos incumplieron la ley o manifestaron intención de hacerlo, con sus actitudes, acciones o lenguaje, en un $30,62 \%$ del tiempo total en que figuraron, y en un $17,74 \%$ demostraron un temperamento agresivo. En la primera variable tuvieron diferencias significativas con los centro y sudamericanos $(p=0,0403)$, los europeos no comunitarios $(p=0,0001)$ y en la segunda solo con estos últimos $(p=0,0008)$.

Aunque no fueron el primer grupo según continente de nacimiento con mayor porcentaje de tiempo con estas características, ambas cifras resultaron elevadas. A su vez, confirman una tendencia que se repitió en los distintos resultados de esta investigación: los grupos con peores indicadores de integración a la sociedad receptora demostraron en mayor proporción de tiempo actitudes negativas ante la ley, agresivas y, en resumen, poca intención de adaptarse a la sociedad receptora.

Esta tendencia en cierta medida justifica con estas características (agresividad y transgresión de la ley) la peor incorporación de estos grupos a la sociedad receptora, pues dichos rasgos los hacen en cierta medida inintegrables. Esta imagen, si es asumida por la población autóctona como si fuera un reflejo de la realidad, podría estar ubicando la responsabilidad de la integración exclusivamente del lado del inmigrante, como si esta fuera solo el resultado -premio o castigo- de un mejor o peor comportamiento de la persona de origen extranjero, sin que la sociedad receptora tenga nada que hacer al respecto. 


\section{Gráfico 16}

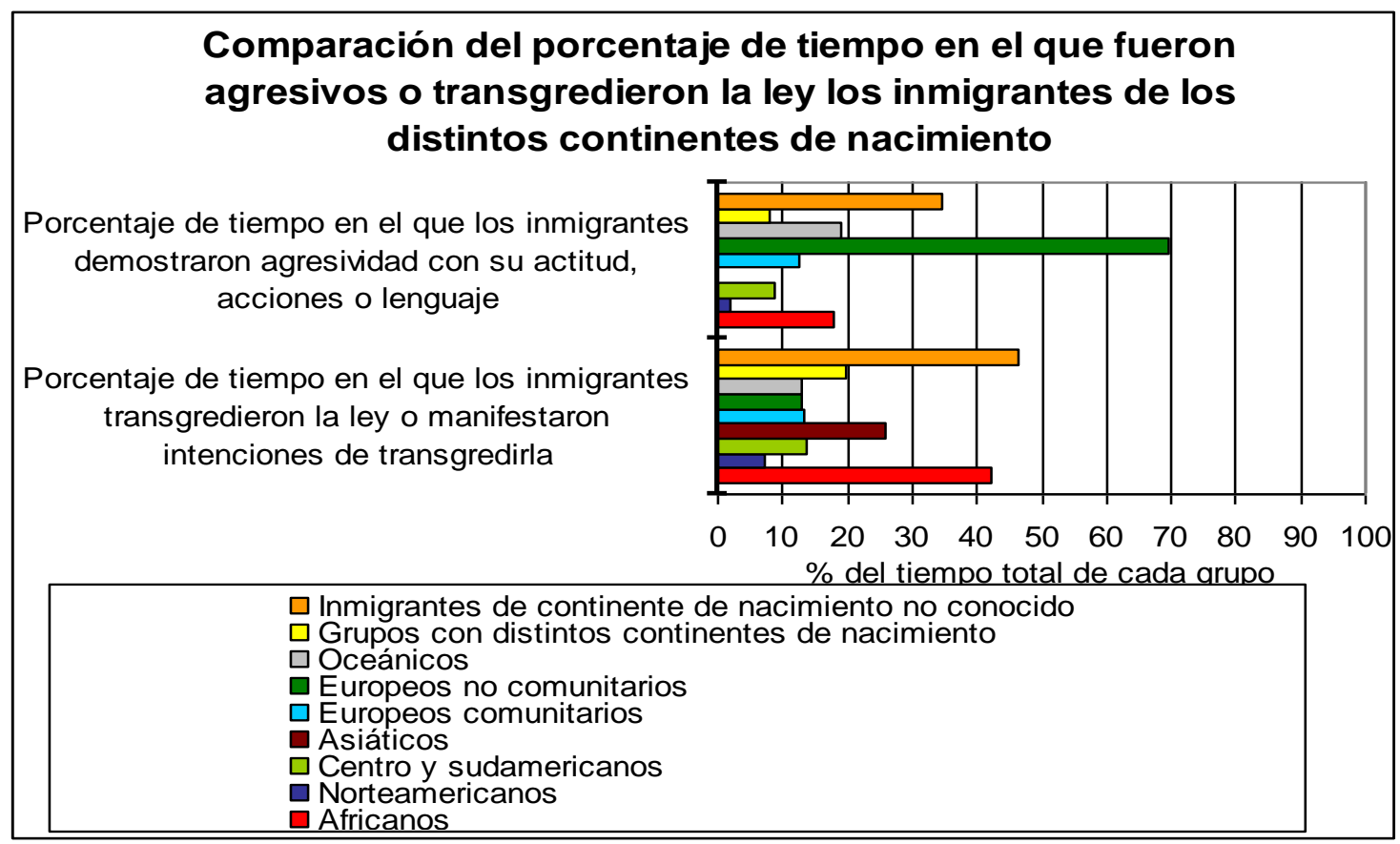

Esta noción podría promover la falta de participación de la población autóctona en la integración, al concebirla como un asunto que el inmigrante debe resolver, y también podría favorecer que no se tenga en cuenta en el debate público toda la complejidad de este proceso y la necesaria colaboración de los nativos.

Asimismo, esta representación podría reforzar el temor de la población nativa ante la diferencia, ante el foráneo, y su calificación de esos grupos de amenaza o peligro, con la consecuente demanda de acciones de vigilancia y coerción por parte del Estado. Ello podría dificultar el establecimiento de relaciones entre autóctonos e inmigrantes en las que ambos grupos intercambien vivencias, experiencias, expresiones culturales, aportes y ayudas mutuas, como según el modelo intercultural debe ocurrir cuando los inmigrantes están integrados. También dificulta el acceso igualitario de estos grupos a las mismas condiciones de trabajo, vivienda, servicios sociales, etc., porque justifica con esas actitudes y acciones agresivas, y con su poco cumplimiento de la ley, su peor situación laboral y socioeconómica.

Y precisamente, en la variable sobre la confianza entre autóctonos e inmigrantes en sus relaciones, las proporciones más altas de la categoría correspondiente a las relaciones desconfiadas y las más bajas de la categoría referida a las relaciones confiadas las obtuvieron, después de los europeos no comunitarios, los africanos (29,64\% y 15,66\%). Tuvieron diferencias significativas, en la primera categoría, con todos los grupos menos con los de distintos continentes de nacimiento y con los europeos no comunitarios; y en la segunda, con los demás menos con estos últimos, los nacidos en Oceanía y los de continente de nacimiento desconocido. 


\section{Gráfico 17}

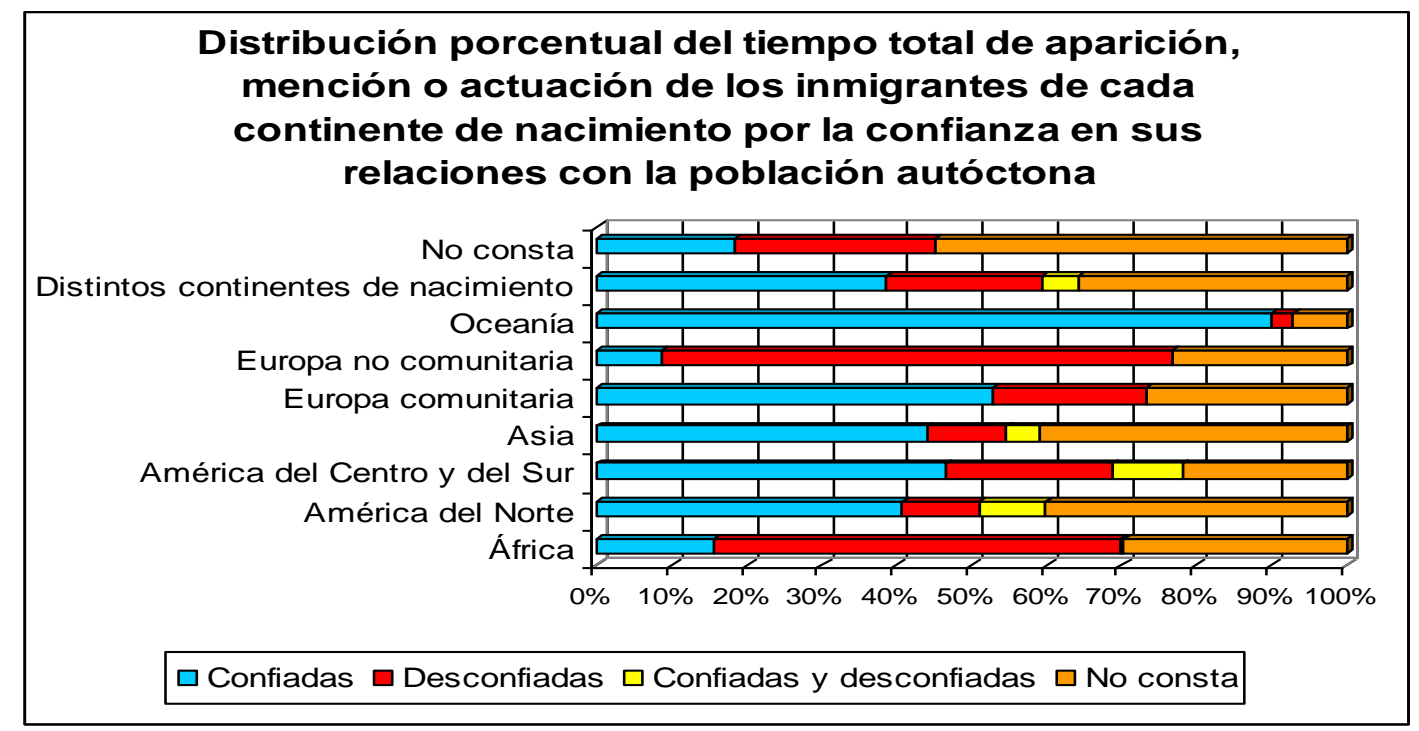

Esta representación podría contribuir a la creación o reforzamiento de la idea de que los grupos con más riesgo de exclusión (por su menor integración socioeconómica) son los establecen menor proporción de vínculos de confianza con los nativos. Si se reproduce esta situación, por asumirla como lo normal o lo más aceptado, se estaría profundizando el aislamiento y disminuyendo los recursos de estos grupos para integrarse, y por tanto se estaría contribuyendo a su discriminación y segregación.

\section{Conclusiones}

África es un continente emisor de migrantes internacionales, principalmente por su acelerado crecimiento poblacional, su índice de desempleo, su precaria situación económica y las deficientes condiciones de vida de sus habitantes. Por estas mismas razones, cuando los africanos emigran, suelen partir de una situación materialmente más difícil que la de otros inmigrantes.

La preocupación por la desfavorable imagen mediática de este colectivo y, en especial, el debate público generado por la llegada por vía marítima de un gran número de inmigrantes indocumentados a las costas españolas, provenientes de Marruecos y de África Subsahariana principalmente, dio origen a diversos estudios sobre el tratamiento del fenómeno migratorio en la radio, la prensa y la televisión. Los resultados de algunas de estas investigaciones indicaban que la representación menos favorable en los géneros informativos era precisamente la de las personas provenientes de África.

Los datos obtenidos en estos estudios y la reflexión sobre la capacidad de los medios de comunicación para influir en la noción que tienen las personas de la realidad social -evidenciada por las teorías de mayor aceptación en la actualidad- motivaron la realización de la presente investigación, en la que se estudiaron las representaciones que ofrece la televisión del fenómeno de la inmigración y de los inmigrantes, no solo en informativos sino en todos los géneros de este medio. Para ello se realizó un análisis de contenido en una muestra de 9595 minutos de la programación televisiva con mayor audiencia. 
En este artículo se resumieron algunos resultados referentes a los nacidos en África, por considerar que la imagen de ellos que transmite la televisión podría condicionar la apertura de la población autóctona para aceptarlos, relacionarse con ellos y colaborar en su integración.

Uno de los resultados más relevantes respecto a los inmigrantes africanos fue su poco frecuente representación: apenas aparecieron o se mencionaron en un 6,09\% del tiempo total en que figuraron personas de origen extranjero. A esta escasa visibilidad se añade que nunca aparecieron en programas de ficción, que desempeñaron con mayor frecuencia que la mayoría de los grupos el rol de sujeto de una noticia o reportaje y que casi tres cuartas partes del tiempo en que aparecieron en informativos lo hicieron en la sección de sucesos. Este último dato y una alta proporción de inmigrantes famosos, del mundo del espectáculo, del deporte o del "corazón", condicionaron que fueran poco representados los inmigrantes comunes, vinculando la imagen de los africanos o bien a los sucesos extraordinarios y negativos de las noticias, o bien a figuras públicas que prácticamente no tienen dificultades para integrarse.

Otro aspecto importante de la imagen televisiva de los inmigrantes africanos, según los resultados de este estudio, fue la alta proporción de desinformación personal y laboral sobre ellos. Se corroboró a través del elevado porcentaje de tiempo en que se seleccionó la categoría No consta en las variables referentes a sus razones de emigración, su intención de permanencia, su situación económica en comparación con la de los nativos, su nivel académico, sus antecedentes penales, su número de hijos, su estado civil y la adecuación de su trabajo a su capacitación. Asimismo, los africanos obtuvieron el porcentaje más elevado de la categoría No consta en las variables sobre su categoría profesional, la autonomía de sus trabajos, la pertenencia de estos a la economía formal o informal, su fuente de ingresos y su principal ocupación.

Los inmigrantes africanos, además, fueron representados en menor porcentaje de tiempo que los otros grupos con un trabajo adecuado a su capacitación, perteneciente a las cuatro primeras categorías profesionales y dentro de la economía formal. A su desempeño laboral se le otorgó menos importancia que en los demás grupos, pues este aspecto se describió en una escasa proporción de tiempo y aparecieron en un bajo porcentaje de tiempo trabajando.

A esta precariedad de sus condiciones de trabajo se unió una mayor tendencia que los demás grupos a desempeñar el rol de víctimas o a tener condiciones de especial vulnerabilidad o dependencia, por la mayor proporción de tiempo en que se mostraron incapaces de resolver por sí mismos sus problemas y por su mayor recurrencia a ayudas gubernamentales y no gubernamentales.

Estas peores condiciones de integración fueron acompañadas por una escasa intención de adaptación a la sociedad receptora, que se pudo apreciar en el mayor porcentaje de tiempo en el que se mostraron transgresores de la ley y tuvieron actitudes, acciones o lenguaje agresivos. Sus relaciones con la población autóctona tuvieron, además, un menor nivel de confianza.

Los rasgos mencionados conforman una imagen de las personas nacidas en África que podría no favorecer que la población autóctona crea que lo normal, lo justo y lo deseable es la igualdad entre ellos y los nativos, sino que, por el contrario, vea en su precariedad la situación normal y habitual.

Por otro lado, esa imagen podría no favorecer que se los valore como necesarios y capaces de hacer aportes importantes a la sociedad, puesto que su vulnerabilidad y dependencia, y su tendencia a desempeñar el rol de víctimas, los muestran como consumidores de ayudas y recursos del Estado y como personas que traen problemas. 
Su poca disposición para integrarse cumpliendo la ley y manteniendo una actitud pacífica podría servir como justificación de sus precarias condiciones laborales y sociales, reforzando a la vez la idea de que la responsabilidad de la integración es principalmente del inmigrante y no de la sociedad receptora. Estas representaciones televisivas no promueven la reflexión sobre la justicia de las leyes de inmigración o la adecuación de las políticas de integración.

De este modo, la televisión no estaría contribuyendo a la integración de los inmigrantes africanos y, por el contrario, la imagen sesgada que de ellos transmite podría convertirse en un factor añadido a las dificultades ya existentes para su proceso de adaptación en la sociedad receptora.

\section{Referencias bibliográficas}

Aparicio, Rosa; Tornos, Andrés y Labrador, Jesús (1999): Inmigrantes, integración, religiones. Madrid: Publicaciones de la Universidad Pontificia de Comillas.

Ardevol Abreu, Alberto (2008): "La inmigración, en la fotografía de prensa de Canarias", en Revista Latina de Comunicación Social 63, La Laguna (Tenerife): http://www.ull.es/publicaciones/latina/08/34 79154 fotoperiodismo/Alberto Ardevol.html (19-1008).

Bidaurratzaga Aurre, Eduardo (2007): "Desarrollo humano en África Subsahariana: evolución y perspectivas de la educación y la salud", en VV.AA., Economía política del desarrollo en África (Carlos Oya y Antonio Santamaría eds.). Madrid: Ediciones Akal, pp. 55-84.

Casero Ripollés, Andreu (2003): "Sin papeles: La identidad de los inmigrantes de los medios de comunicación", en VV.AA., La pantalla de las identidades: medios de comunicación, políticas y mercados de identidad (Víctor Francisco Sampedro ed.). Barcelona: Icaria, pp. 233-257.

CES Consejo Económico y Social de Canarias (2008): "El reto de la inmigración", en Canarias ante el futuro de las regiones ultraperiféricas de la Unión Europea. Gobierno de Canarias: http://www.cescanarias.org/documentos/rup/inmigracion.pdf (03-05-2010).

CIS Centro de Investigaciones Sociológicas (2008): Estudio 2773. Actitudes ante la inmigración (II),

Madrid:

http://www.cis.es/cis/opencm/ES/1 encuestas/estudios/ver.jsp?estudio=9680\&cuestionario=11234 \&muestra=16905 (09-02-10)

Galán Fajardo, Elena (2006): "La representación de los inmigrantes en la ficción televisiva en España. Propuesta para un análisis de contenido. El Comisario y Hospital Central", en Revista Latina de Comunicación Social 61, La Laguna (Tenerife): http://www.ull.es/publicaciones/latina/200608galan.htm (15-01-08).

García Añon, José (2003): "Inmigración y derechos de ciudadanía. La integración de los inmigrantes en las políticas públicas locales y autonómicas", en VV.AA. Perspectivas de la inmigración en España. Una aproximación desde el territorio (Gemma Aubarell dir.). Barcelona: Icaria Atrazit Mediterráneo, pp. 81-127.

García Castaño, E. Javier; Granados Martínez, Antolín y Capellán de Toro, Lorenzo (2003): "Presencia e imagen de la inmigración extranjera en Andalucía", en VV.AA. Perspectivas de la inmigración en España. Una aproximación desde el territorio (Gemma Aubarell dir.). Barcelona: Icaria Atrazit Mediterráneo, pp. 81-127. 
Gerbner, George (1969): "Toward 'Cultural Indicators': The Analysis of Mass Mediated Public Message System", en VV.AA., The Analysis of Communication Content: Developments in Scientific Theories and Computer Techniques (George Gerbner ed.). New York: John Wiley \& Sons, pp. 123-132.

Guisán, M. Carmen y Expósito, Pilar (2001): "Educación, desarrollo y emigración en África", en Estudios Económicos de Desarrollo Internacional vol. 1, n. 2. Asociación Euro-Americana de Estudios de Desarrollo Económico, Universidad Santiago de Compostela, pp. 1-13: http://redalyc.uaemex.mx/redalyc/pdf/165/16510201.pdf (01-05-2010).

Instituto Nacional de Estadística INE (2010a): "Internacional", Inebase, Madrid: http://www.ine.es/jaxi/menu.do?type=pcaxis\&path=\%2Ft42/p02/\&file=inebase\&L=0 (04-05-2010).

Instituto Nacional de Estadística INE (2010b): "Padrón municipal: explotación estadística y Nomenclátor", Inebase, en línea en http://www.ine.es/jaxi/menu.do?type=pcaxis\&path=/t20/e245/\&file=inebase (03-05-2010).

Lorite García, Nicolás (dir.) (2004): Tratamiento informativo de la inmigración en España 2002. Madrid: Ministerio del Trabajo y Asuntos Sociales, Instituto de Migraciones y Servicios Sociales (IMSERSO):

http://www.oberaxemtas.upcomillas.es/Publicaciones/Libros/tratamiento/tratamiento.htm (01-1005).

Merino Arribas, María Adoración (2009): Inmigración irregular africana y prensa en Canarias (1999-2003). Santa Cruz de Tenerife: Ediciones Idea.

Martínez Pastor, E. y Vizcaíno-Laorga, R. (2008): "Publicidad institucional como fenómeno integrador ante la inmigración en España: régimen jurídico", en Revista Latina de Comunicación Social 63, La Laguna http://www.revistalatinacs.org/ 2008/10 Fuenlabrada/Vizcaino y Martinez.html (19-10-09).

Millet, Daniel (2007): "Los sin derechos. Una investigación sobre la inmigración irregular descubre las claves del fenómeno en Canarias", La Opinión de Tenerife, Santa Cruz de Tenerife, 1 de octubre 2007: http://www.laopinion.es/secciones/noticia.jsp?pRef=2910 9106057 SOCIEDAD-derechos (01-10-07).

Muñiz, Carlos e Igartua, Juan José (2004): "Encuadres noticiosos e inmigración. Un análisis de contenido de la prensa y televisión española", en Zer. Revista de estudios de comunicación 16, País Vasco, mayo: http://www.ehu.es/zer/zer16/articulo6.htm (10-12-05).

Musterd, Sako (2003): "Segregation and Integration: a Contested Relationship", Journal of Ethnic and Migration Studies Vol. 29, № 4, Sussex (Reino Unido), Centre for Migration Research at the University of Sussex, pp. 623-641.

OIT Organización Internacional del Trabajo (2010): "En busca de trabajo: un nuevo estudio de la OIT sobre migración laboral en África del Norte y Occidental", Ginebra (Suiza): http://www.ilo.org/global/About the ILO/Media and public information/Feature stories/lang-es/WCMS 126505/index.htm (06-05-2010).

Pablos Coello, José Manuel de y Ardebol Abreu, Alberto (2008): "Medios de comunicación social", en VV.AA., La integración cultural y social de los inmigrantes latinoamericanos: Inquietudes y sugerencias para políticas de cambio (Lidia Cabrera Pérez coord.). Madrid: Editorial Universitas. 
Pajares, Miguel (2005): La integración ciudadana. Una perspectiva para la inmigración. Barcelona: Icaria Editorial.

PNUD Programa de las Naciones Unidas para el Desarrollo (2007): Informe sobre desarrollo humano, Nueva York: http://hdr.undp.org/es/paises/region/ (04-05-2010).

Rodríguez Díaz, Raquel y Mena Montes, Noemí (2008): «Opinión Pública y frames: La crisis de los cayucos», en Revista Latina de Comunicación Social 63, La Laguna (Tenerife): http://www.ull.es/publicaciones/latina/08/28 46 Vicalvaro/Raquel Rodriguez y Noemi Mena.html (19-10-09).

Ruiz, Xavier; Ferrer, Joan; Obradors, Matilde; Pujadas, Eva y Pérez, Oliver (2007): "Los roles narrativos del inmigrante en la ficción televisiva. El caso de la ficción española de producción propia", en VV.AA., Medios de comunicación, inmigración y sociedad (Juan José Igartua y Carlos Muñiz coords.). Salamanca: Universidad de Salamanca, pp. 111-126.

Sabés Turmo, Fernando (2010): "Análisis del tratamiento del fenómeno migratorio en www.elpais.com", en Revista Latina de Comunicación Social 65, La Laguna (Tenerife): http://www.revistalatinacs.org/10/art/881 UAB/03 Sabes.html (12-02-10).

Sierra Bravo, R. (1999): Técnicas de investigación social. Teoría y ejercicios Madrid: Editorial Paraninfo.

Torres, Francisco (2002): "La integración de los inmigrantes y algunos de los desafíos que nos plantea", en VV.AA., Inmigrantes: ¿cómo los tenemos? Algunos desafíos y (malas) respuestas (Francisco Javier de Lucas y Francisco Torres eds.). Madrid: Editorial Talasa Ediciones S. L., pp. 49-73.

Villafañe, Justo y Mínguez, Norberto (1996): Principios de teoría general de la imagen. Madrid: Ediciones Pirámide.

* La autora quiere manifestar su agradecimiento a su director de tesis doctoral Dr. José Manuel Pestano y a la antropóloga y especialista en Estadística Greta Rodríguez de Arroyo. 